\title{
The improvement of soil thermodynamics and its effects on land surface meteorology in the IPSL climate model
}

\author{
F. Wang, F. Cheruy, and J.-L. Dufresne \\ Laboratoire de Météorologie Dynamique du CNRS, Tour 45-55, 3ème étage, Case Postale 99, 4 place Jussieu, \\ 75252 Paris CEDEX 05, France \\ Correspondence to: F. Wang (fuxing.wang@1md.jussieu.fr)
}

Received: 13 July 2015 - Published in Geosci. Model Dev. Discuss.: 2 October 2015

Revised: 30 November 2015 - Accepted: 4 January 2016 - Published: 28 January 2016

\begin{abstract}
This paper describes the implementation of an improved soil thermodynamics in the hydrological module of Earth system model (ESM) developed at the Institut Pierre Simon Laplace (IPSL) and its effects on land surface meteorology in the IPSL climate model. A common vertical discretization scheme for the soil moisture and for the soil temperature is adopted. In addition to the heat conduction process, the heat transported by liquid water into the soil is modeled. The thermal conductivity and the heat capacity are parameterized as a function of the soil moisture and the texture. Preliminary tests are performed in an idealized 1-D (one-dimensional) framework and the full model is then evaluated in the coupled land-atmospheric module of the IPSL ESM. A nudging approach is used in order to avoid the timeconsuming long-term simulations required to account for the natural variability of the climate. Thanks to this nudging approach, the effects of the modified parameterizations can be modeled. The dependence of the soil thermal properties on moisture and texture lead to the most significant changes in the surface energy budget and in the surface temperature, with the strongest effects on the surface energy budget taking place over dry areas and during the night. This has important consequences on the mean surface temperature over dry areas and during the night and on its short-term variability. The parameterization of the soil thermal properties could therefore explain some of the temperature biases and part of the dispersion over dry areas in simulations of extreme events such as heat waves in state-of-the-art climate models.
\end{abstract}

\section{Introduction}

The soil thermodynamics implemented in the land surface models (LSMs) partly controls the energy budget at the land surface. Most of the LSMs rely on the resolution of a Fourier Law of diffusion equation for heat with a zero flux condition at a limited soil depth and use classical numerical methods to solve it (Lawrence et al., 2011; Ekici et al., 2014). However, differences are identified in adopted soil depth, in the vertical discretization of the numerical schemes, in the additional physical processes other than heat diffusion taken into account and in the degree of complexity of the parameterization of thermal properties.

Several studies investigated the effect of the bottom boundary depth of LSMs on the evolution of the subsurface temperature (e.g. Lynch-Stieglitz, 1994; Stevens et al., 2007). Sun and Zhang (2004) suggested that at least 6-15 m depth is required to simulate the temperature annual cycle. However, the location of the lower boundary in LSMs used in climate models with identical heat transfer processes ranges from 2 to $10 \mathrm{~m}$ (Anderson et al., 2004; Table 1).

The heat transfer into the soil results from both heat conduction and heat transport by liquid water (e.g. Saito et al., 2006). The heat transported by liquid water can modify the temperature at the surface and below (e.g. Gao et al., 2003, 2008) but this latter process is often neglected in LSMs (Wei et al., 2014). Several studies investigated the influence of this process on the land-surface variables based on 1-D (onedimensional) experiments based on site observations (e.g. Kollet et al., 2009). However, to our knowledge, the impact of the heat convection has never been evaluated on the global scale. 
Table 1. The list of soil thermodynamics parameterizations in different LSMs/GCMs.

\begin{tabular}{|c|c|c|c|c|}
\hline Model & $\begin{array}{l}\text { Soil depth }(\mathrm{m}) / \text { layers } \\
\text { for moisture and } \\
\text { temperature }\end{array}$ & $\begin{array}{l}\text { Soil thermal property } \\
\text { (thermal conductivity } \lambda \text { and } \\
\text { heat capacity } C_{\mathrm{P}} \text { ) }\end{array}$ & $\begin{array}{l}\text { Soil heat } \\
\text { conduction and } \\
\text { convection pro- } \\
\text { cesses }\end{array}$ & Reference \\
\hline $\begin{array}{l}\text { Community Land Model (CLM4) included } \\
\text { in Community Climate System Model- } \\
\text { CCSM3 }\end{array}$ & $42.10 / 15 \mathrm{~L}$ and $3.8 / 10 \mathrm{~L}$ & $\begin{array}{l}\lambda: \mathrm{J} 75 ; C_{\mathrm{P}}: \text { de Vries }(1963) \\
\text { organic matter included }\end{array}$ & Conduction & $\begin{array}{l}\text { Lawrence et al. }(2008,2011) ; \\
\text { Lawrence and Slater }(2008)\end{array}$ \\
\hline $\begin{array}{l}\text { Organizing Carbon and Hydrology In Dy- } \\
\text { namic EcosystEms (ORCHIDEE) of Insti- } \\
\text { tute Pierre Simon Laplace Climate Model } \\
\text { (IPSL-CM) }\end{array}$ & $2.0 / 11 \mathrm{~L}$ and $5.0 / 7 \mathrm{~L}$ & Depending on soil moisture & Conduction & $\begin{array}{l}\text { Krinner et al. (2005); Dufresne } \\
\text { et al. (2013); Gouttevin et al. (2012) }\end{array}$ \\
\hline $\begin{array}{l}\text { the Joint UK Land Environment Simulator } \\
\text { (JULES) in the Met Office Unified Model } \\
\text { (MetUM) }\end{array}$ & $2.0 / 4 \mathrm{~L}$ and $2.0 / 4 \mathrm{~L}$ & $\begin{array}{l}\lambda: \text { J75, Cox et al. (1999); } \\
C_{\mathrm{P}}: \text { Cox et al. (1999) }\end{array}$ & $\begin{array}{l}\text { Conduction and } \\
\text { Convection by } \\
\text { water vapor }\end{array}$ & $\begin{array}{l}\text { Best et al. (2011); Garcia Gonzalez } \\
\text { et al. (2012) }\end{array}$ \\
\hline $\begin{array}{l}\text { Hydrology-Tiled ECMWF Scheme for Sur- } \\
\text { face Exchange over Land (H-TESSEL) }\end{array}$ & $2.89 / 4 \mathrm{~L}$ and $2.89 / 4 \mathrm{~L}$ & $\lambda: \mathrm{J} 75 ; C_{\mathrm{P}}: 2.19 \times 10^{6}$ & Conduction & $\begin{array}{l}\text { Hazeleger et al. (2011); van den } \\
\text { Hurk et al. (2000) }\end{array}$ \\
\hline $\begin{array}{l}\text { Jena Scheme for Biosphere-Atmosphere } \\
\text { Coupling in Hamburg (JSBACH)-Earth } \\
\text { system model of Max Planck Institute for } \\
\text { Meteorology (MPI-ESM) }\end{array}$ & $10 / 5 \mathrm{~L}$ and $10 / 5 \mathrm{~L}$ & $\lambda: \mathrm{J} 75 ; C_{\mathrm{P}}:$ de Vries (1963) & Conduction & Ekici et al. (2014) \\
\hline $\begin{array}{l}\text { Interaction between soil-biosphere- } \\
\text { atmosphere (ISBA) LSM in CNRM-CM }\end{array}$ & $2-3 / 10-11 \mathrm{~L}$ and $12 / 14 \mathrm{~L}$ & $\lambda: \mathrm{J} 75 ; C_{\mathrm{P}}:$ de Vries (1963) & Conduction & Decharme et al. (2013) \\
\hline Noah LSM & $2 / 4 \mathrm{~L}$ and $2 / 4 \mathrm{~L}$ & $\lambda: \mathrm{J} 75 ; C_{\mathrm{P}}:$ de Vries (1963) & Conduction & Ek et al. (2003) \\
\hline
\end{tabular}

The soil thermal conductivity and the soil heat capacity control the evolution of the subsurface temperature and the energy exchanges between the atmosphere boundary layer and the land surface. Besides water content, the soil thermal properties are affected by many factors such as soil types, soil porosity, and dry density (Peters-Lidard et al., 1998; Lawrence and Slater, 2008). The level of complexity of the parameterization of the thermal properties in state-of-the-art LSMs is highly variable (e.g. Balsamo et al., 2009; Gouttevin et al., 2012). Moreover, whereas the soil heat transfer and the moisture diffusion are coupled through the moisture dependence of the thermal properties, the equations of the soil heat transfer and those of moisture diffusion are often solved on different grids. This choice, made for numerical reasons, can lead to energy conservation issues and a unified vertical discretization might be more appropriate.

This paper describes the implementation of an improved soil thermodynamics in the Organizing Carbon and Hydrology In Dynamic Ecosystems (ORCHIDEE; Krinner et al., 2005) LSM. The following issues are addressed: (1) the implementation of the same vertical discretization scheme for soil moisture and soil temperature in climate models, (2) the coupling of soil heat convection by liquid water transfer with soil heat conduction process, (3) the parameterization of the thermal conductivity and heat capacity as a function of soil moisture and texture, and (4) the sensitivity of the relevant near surface climate variables simulated by a coupled landatmospheric model to the soil vertical discretization, the soil heat convection processes, and to the soil thermal properties. The ORCHIDEE LSM is coupled to the atmospheric model
LMDZ (developed at the Laboratoire de Météorologie Dynamique), whose physical parameterizations are described in Hourdin et al. (2013) and in Rio et al. (2013). LMDZOR refers to the atmosphere-land component of the Institute Pierre Simon Laplace Climate Model (IPSL-CM; Dufresne et al., 2013). In the standard version of ORCHIDEE, the soil heat transfer is solved with a classical 1-D soil heat conduction approach (Hourdin, 1992). The soil heat convection in ORCHIDEE is neglected. The vertical grid for temperature and moisture are different; the soil depth for the temperature is $5 \mathrm{~m}$ with 7 layers $(5 \mathrm{M} 7 \mathrm{~L}$ hereafter) and $2 \mathrm{~m}$ for the moisture with 11 layers $(2 \mathrm{M} 11 \mathrm{~L}$ hereafter). The moisture profile must therefore be interpolated when diagnosing the soilmoisture-dependent soil thermal conductivity and the soil heat capacity in order to solve the soil heat transfer equation.

The new developments for the soil thermodynamics, the soil heat conduction-convection model, its boundary conditions, the choice of the soil depth and the vertical grid are described in Sect. 2. Land-surface-atmosphere coupled sensitivity experiments are performed with the full 3-D LMDZOR model and analyzed in Sect. 3 to evaluate the impact of the new developments for the soil thermodynamics on the global scale. The impact of the soil thermodynamics on the global mean surface temperature and on the short-term temperature variability are discussed in Sect. 4. Conclusions are drawn in Sect. 5. 


\section{The soil thermodynamics model}

\subsection{Model description}

The governing equation for heat conduction coupled with the energy transferred by liquid water transport in the soil is described by the following energy conservation equation (Saito et al., 2006):

$$
\begin{aligned}
C_{\mathrm{P}}(\theta, \mathrm{st}) \frac{\partial T}{\partial t} & =\frac{\partial}{\partial z}\left[\lambda(\theta, \mathrm{st}) \frac{\partial T}{\partial z}\right]-C_{\mathrm{W}} \frac{\partial q_{\mathrm{L}} T}{\partial z} \\
& -C_{\mathrm{W}} \mathrm{ST},
\end{aligned}
$$

where $C_{\mathrm{P}}$ and $C_{\mathrm{W}}$ are volumetric heat capacities $\left(\mathrm{J} \mathrm{m}^{-3} \mathrm{~K}^{-1}\right)$ of moist soil and liquid water, respectively; $\theta$ is the volumetric soil moisture $\left(\mathrm{m}^{3} \mathrm{~m}^{-3}\right)$; st stands for the soil texture; $T$ is the soil temperature $(\mathrm{K}) ; t$ is the time $(\mathrm{s}) ; z$ is the soil depth (m); $\lambda$ is the soil thermal conductivity $\left(\mathrm{J} \mathrm{m}^{-1} \mathrm{~s}^{-1} \mathrm{~K}^{-1}\right) ; q_{\mathrm{L}}$ is the flux density of liquid water $\left(\mathrm{m} \mathrm{s}^{-1}\right) ; C_{\mathrm{W}} \mathrm{ST}$ represents a sink of energy associated with the root water uptake that can be neglected for bare soil (i.e. without any plant); and $S$ is the transpiration amount per second $\left(\mathrm{m}^{-3} \mathrm{~m}^{-3} \mathrm{~s}^{-1}\right)$.

Equation (1) is solved using an implicit finite difference method (FDM) with zero heat flux condition at the lower boundary of LSM (see Appendix A; Hourdin, 1992). The bedrock effects in deep soil are not parameterized. At the surface, the energy budget equation is:

$C_{\mathrm{S}} \frac{\partial T_{\mathrm{S}}}{\partial t}=F_{\mathrm{rad}}+F_{1}^{\mathrm{h}}+\mathrm{LF}_{1}^{q}+G_{1}+H_{1}$

$H_{1}=C_{\mathrm{W}}\left(T_{\text {rain }}-T_{\mathrm{S}}\right) q_{\mathrm{L}, 0}$,

where $G_{1}$ is the soil heat flux due to heat conduction process; $H_{1}$ is the sensible heat flux of rainfall due to the difference of temperature between the rainwater and the soil surface (Kollet et al., 2009); $T_{\text {rain }}$ and $T_{\mathrm{S}}$ are the temperature of the rainfall and the soil surface, respectively (K); $q_{\mathrm{L}, 0}$ is the infiltrated water flux $\left(\mathrm{m} \mathrm{s}^{-1}\right) ; F_{\text {rad }}, F_{1}^{\mathrm{h}}$, and $\mathrm{LF}_{1}^{q}$ are the net radiation, sensible heat and latent heat flux respectively $\left(\mathrm{W} \mathrm{m}^{-2}\right)$; $C_{\mathrm{S}}$ is the "layer" heat capacity per unit area $\left(\mathrm{J} \mathrm{m}^{-2} \mathrm{~K}^{-1}\right)$ and is related to the thickness of the first soil layer. $T_{\text {rain }}$ is estimated by wet bulb temperature (Gosnell et al., 1995).

In the baseline model, the soil heat transfer is represented by classical soil heat conduction process, and the terms $-C_{\mathrm{W}} \frac{\partial q_{\mathrm{L}} T}{\partial z}-C_{\mathrm{W}} \mathrm{ST}$ in Eq. (1) and $H_{1}$ in Eq. (2) are not included. These two terms describe the energy transferred by liquid water movement in the soil and at the soil surface. The motivation of developing these processes is to represent the energy budget possibly close to the real world in the earth system model. Although the amount of energy by heat convection could be small at large timescale (e.g., monthly), the other components of the earth modeling system could be influenced through land surface temperature and surface energy budget (Wei et al., 2014). Therefore, it is necessary to include these processes in the earth system model.
The unsaturated soil water flow is described by the 1-D Fokker-Planck equation obtained by combining the equation of motion (i.e. Darcy law applied to unsaturated 1-D ground water flow in an isotropic and homogeneous soil) with the mass balance equation (de Rosnay et al., 2000):

$$
\begin{aligned}
& q_{\mathrm{L}}(z, t)=-D(\theta(z, t)) \frac{\partial \theta(z, t)}{\partial z}+K(\theta(z, t)), \\
& \frac{\partial \theta(z, t)}{\partial t}=-\frac{\partial q_{\mathrm{L}}(z, t)}{\partial z}-S(\theta),
\end{aligned}
$$

where $K(\theta)$ and $D(\theta)$ are the hydraulic conductivity $\left(\mathrm{m} \mathrm{s}^{-1}\right)$ and diffusivity $\left(\mathrm{m}^{2} \mathrm{~s}^{-1}\right)$, respectively.

\subsection{The parameterization of soil thermal properties}

$\lambda$ and $C_{\mathrm{P}}$ are parameterized as a function of moisture and texture (Fig. 1). $C_{\mathrm{P}}$ is computed as the sum of heat capacities of soil and water (de Vries, 1963; Yang and Koike, 2005; Abu-Hamdeh, 2003),

$C_{\mathrm{P}}(\theta, \mathrm{st})=C_{\mathrm{v}, \mathrm{d}}(\mathrm{st})+\frac{W(\theta, \mathrm{st})}{\Delta z} \times C_{\mathrm{W}}$,

where $C_{\mathrm{v}, \mathrm{d}}$ is the volumetric heat capacity for dry soil $\left(\mathrm{J} \mathrm{m}^{-3} \mathrm{~K}^{-1}\right) ; W$ is the total water content in the soil layer (m); $\Delta z$ is the thickness of the soil layer (m), and $C_{\mathrm{v}, \mathrm{d}}$ is prescribed and taken from Pielke (2002) (P02, Table 2).

There are many ways to compute the soil thermal conductivity, including the method proposed by Johansen (1975; J75 hereafter) recommended by many studies (e.g. Peters-Lidard et al., 1998). Here, the soil freezing process is neglected. The equation for the soil thermal conductivity is given by:

$$
\begin{aligned}
& \lambda(\theta, \mathrm{st})=\left\{0.7 \times \log \left[\frac{\theta(\mathrm{st})}{n_{\mathrm{p}}(\mathrm{st})}\right]+1.0\right\} \\
& \times\left[\lambda_{\text {sat }}(\mathrm{st})-\lambda_{\text {dry }}(\mathrm{st})\right]+\lambda_{\text {dry }}(\mathrm{st}), \\
& \lambda_{\text {dry }}(\mathrm{st})=\frac{0.135 \times\left[1-n_{\mathrm{p}}(\mathrm{st})\right] \times 2700+64.7}{2700-0.947 \times\left[1-n_{\mathrm{p}}(\mathrm{st})\right] \times 2700}, \\
& \lambda_{\text {sat }}(\mathrm{st})=\left[\left(\lambda_{\mathrm{q}}^{q(\mathrm{st})} \lambda_{\mathrm{o}}^{1-q(\mathrm{st})}\right)\right]^{1-n_{\mathrm{p}}(\mathrm{st})} \lambda_{\mathrm{w}}^{n_{\mathrm{p}}(\mathrm{st})},
\end{aligned}
$$

where $\lambda_{\text {dry }}$ and $\lambda_{\text {sat }}$ are the dry and saturated thermal conductivity, respectively $\left(\mathrm{W} \mathrm{m}^{-1} \mathrm{~K}^{-1}\right) ; \lambda_{\mathrm{w}}, \lambda_{\mathrm{q}}$, and $\lambda_{\mathrm{o}}$ are the thermal conductivity of water, quartz, and other minerals, respectively $\left(\mathrm{W} \mathrm{m}^{-1} \mathrm{~K}^{-1}\right) ; n_{\mathrm{p}}$ is the soil porosity; and $q$ is the quartz content. The variables $n_{\mathrm{p}}$ and $q$ depend on the soil texture (Table 2). The soil thermal conductivity at the layer interface is linearly interpolated according to the thickness of the layers using the soil thermal conductivity at the nodes where the soil moisture is computed.

The soil thermal inertia $\left(I, \mathrm{~W} \mathrm{~m}^{-2} \mathrm{~K}^{-1} \mathrm{~s}^{0.5}\right)$ and the soil heat diffusivity $\left(K_{T}, \mathrm{~m}^{2} \mathrm{~s}^{-1}\right)$ are introduced to help interpreting the results. The soil thermal inertia measures the resistance of the soil to a temperature change induced by an external periodic forcing. The higher $I$ is, the slower the 

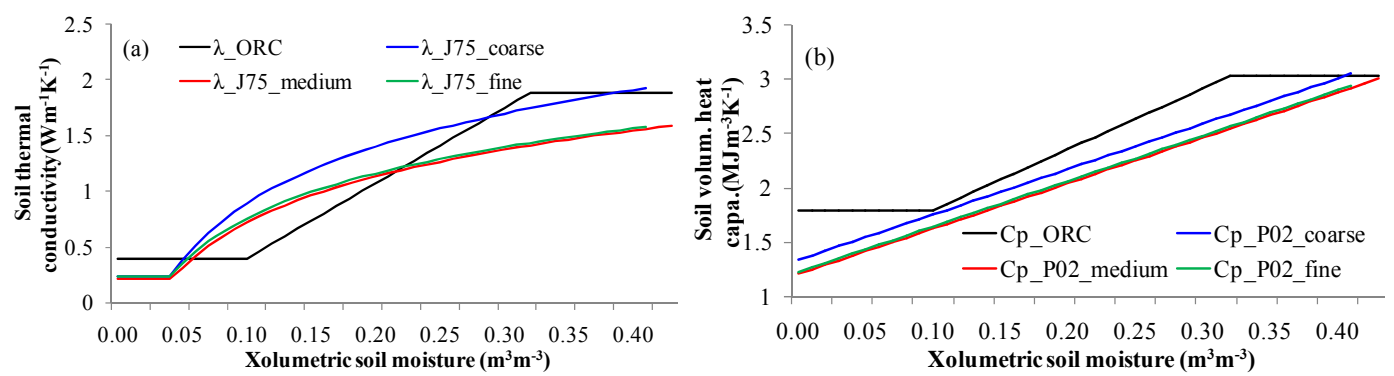

Figure 1. The variation of (a) soil thermal conductivity $\lambda$ and (b) soil heat capacity $C_{\mathrm{P}}$ with volumetric soil moisture for different soil textures (coarse, medium, fine) by using ORCHIDEE standard parameterization (black line) and the revised parameterization ( $\lambda$ is revised by using $\mathrm{J} 75$ method, and $C_{\mathrm{P}}$ is revised by using P02 data). The coarse, medium, and fine soil are shown in blue, red, and green lines, respectively.

Table 2. The soil thermal property parameters.

\begin{tabular}{llrrr}
\hline Item & Unit & \multicolumn{3}{c}{ Values } \\
\hline Volumetric water heat capacity $\left(C_{\mathrm{w}}\right)$ & $\mathrm{J} \mathrm{m}^{-3} \mathrm{~K}^{-1}$ & \multicolumn{2}{c}{$4.186 \times 10^{6}$} \\
Thermal conductivity of water $\left(\lambda_{\mathrm{w}}\right)$ & $\mathrm{W} \mathrm{m}^{-1} \mathrm{~K}^{-1}$ & \multicolumn{2}{c}{0.57} \\
Thermal conductivity of quartz $\left(\lambda_{\mathrm{q}}\right)$ & $\mathrm{W} \mathrm{m}^{-1} \mathrm{~K}^{-1}$ & \multicolumn{2}{c}{7.7} \\
Thermal conductivity of other minerals $\left(\lambda_{\mathrm{o}}\right)$ & $\mathrm{W} \mathrm{m}^{-1} \mathrm{~K}^{-1}$ & 2.0 (for $q>0.2) ; 3.0$ (others) \\
Soil texture & & Coarse & Medium & Fine \\
Dry soil volumetric heat capacity $\left(C_{\mathrm{v}, \mathrm{d}}\right)$ & $\mathrm{J} \mathrm{m}^{-3} \mathrm{~K}^{-1}$ & $1.34 \times 10^{6}$ & $1.21 \times 10^{6}$ & $1.2 \times 10^{6}$ \\
Soil porosity $\left(n_{\mathrm{p}}\right)$ & - & 0.41 & 0.43 & 0.41 \\
Quartz content $(q)$ & - & 0.60 & 0.40 & 0.35 \\
\hline
\end{tabular}

The $\lambda_{\mathrm{w}}, \lambda_{\mathrm{q}}, \lambda_{\mathrm{o}}, n_{\mathrm{p}}$ and $q$ are obtained from Peters-Lidard et al. (1998). The $C_{\mathrm{v}, \mathrm{d}}$ is obtained from Pielke (2002). The coarse, medium and fine soil textures correspond to the sandy loam, loam, and clay loam USDA textures classes, respectively.

temperature varies during a full heating-cooling cycle (e.g., $24 \mathrm{~h}$ day). $K_{T}$ depicts the ability of the soil to diffuse heat. The larger $K_{T}$ is, the more rapidly the heat diffuses into the ground.

$$
\begin{aligned}
& I(\theta, \mathrm{st})=\sqrt{\lambda(\theta, \mathrm{st}) \times C_{\mathrm{P}}(\theta, \mathrm{st})}, \\
& K_{T}(\theta, \mathrm{st})=\frac{\lambda(\theta, \mathrm{st})}{C_{\mathrm{P}}(\theta, \mathrm{st})} .
\end{aligned}
$$

\subsection{The vertical discretization in the soil thermodynamics model}

A common vertical discretization for the soil moisture and for the soil temperature is proposed (Fig. 2c). Using this discretization, the soil moisture profile does not need to be interpolated in order to diagnose the moisture-dependent thermal properties when solving the heat transfer equation, as it is done in the standard version of ORCHIDEE. For the first $2 \mathrm{~m}$, the same vertical discretization as the one used for the moisture in the standard version of ORCHIDEE is adopted (de Rosnay et al., 2000; Fig. 2b). The distance of the nodes in each layer below $2 \mathrm{~m}$ is fixed to $1 \mathrm{~m}$ (i.e. the largest node distance for 2M11L).

The minimum soil depth $\left(\mathrm{DD}_{y}\right)$ required to properly simulate the temperature / heat flux annual cycle with a zero-flux assumption is estimated as the depth where the amplitudes of temperature and soil heat flux variations attenuate to $e^{-3}$ of the annual amplitude at the surface (Sun and Zhang, 2004):

$\mathrm{DD}_{y}\left(\theta, q_{\mathrm{L}}, \mathrm{st}\right)=\sqrt{365} \times \mathrm{DD}_{d}\left(\theta, q_{\mathrm{L}}, \mathrm{st}\right)$

with

$$
\frac{\mathrm{DD}_{d}\left(\theta, q_{\mathrm{L}}, \mathrm{st}\right)=}{2 W_{\mathrm{L}}\left(\theta, q_{\mathrm{L}}, \mathrm{st}\right)+\sqrt{2}\left\{W_{\mathrm{L}}\left(\theta, q_{\mathrm{L}}, \mathrm{st}\right)^{2}+\left[W_{\mathrm{L}}\left(\theta, q_{\mathrm{L}}, \mathrm{st}\right)^{4}+4 \omega^{4} D(\theta, \tau, \mathrm{st})^{4}\right]^{\frac{1}{2}}\right\}^{\frac{1}{2}}},
$$

$W_{\mathrm{L}}\left(\theta, q_{\mathrm{L}}, \mathrm{st}\right)=-\frac{C_{\mathrm{W}}}{C_{\mathrm{P}}(\theta, \mathrm{st})} q_{\mathrm{L}}$

$D(\theta, \mathrm{st})=\left[\frac{\tau}{\pi} \times K_{T}(\theta, \mathrm{st})\right]^{1 / 2}$,

where $W_{\mathrm{L}}$ is the liquid water flow rate $\left(\mathrm{m}^{3} \mathrm{~m}^{-2} \mathrm{~s}^{-1}\right)$ and $\tau$ is the harmonic period of the surface temperature $(\tau=86400 \mathrm{~s}$, for the diurnal cycle). The soil damping depth ( $\mathrm{DD}_{d}$, unit: $\mathrm{m}$ ) is the depth at which the temperature amplitude decreases to the fraction $e^{-3}$ of the surface daily amplitude. $\mathrm{DD}_{d}$ can be computed from the analytical solution of the coupled soil conduction-convection model under a steady water flow $(\lambda$, $C_{\mathrm{P}}, q_{\mathrm{L}}$ are constant and $C_{\mathrm{W}} \mathrm{ST}$ is 0 in Eq. (1); Gao et al., 2003, 2008). $\mathrm{DD}_{d}$ and $\mathrm{DD}_{y}$ depend on the soil properties and on the liquid water flux. 
(a) 5M7L for soil temperature

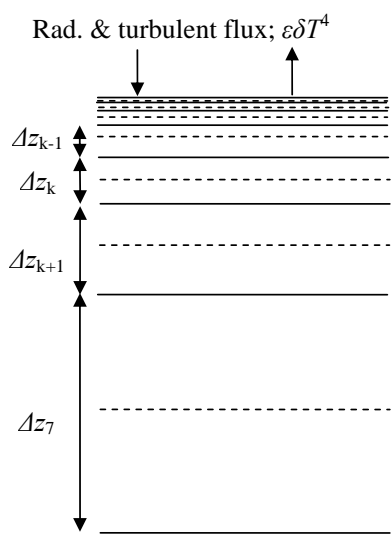

(b) 2M11L for soil moisture

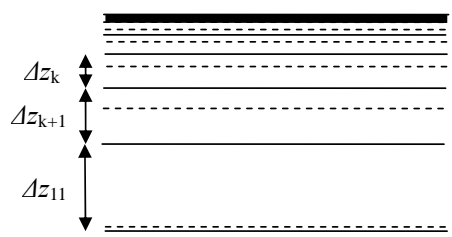

(c) Revised 8M17L for moisture and temperature
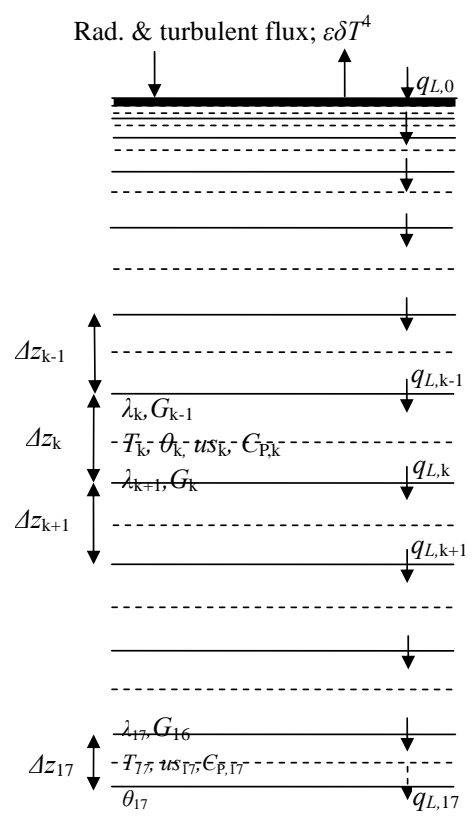

Figure 2. The soil vertical discretization of (a) 5M7L (Hourdin, 1992), (b) 2M11L (de Rosnay et al., 2000), and (c) 8M17L (new). The dashed and solid lines are the node and interface, respectively. For $2 \mathrm{M} 11 \mathrm{~L}$, the top layer/bottom layer node and interface are at the same position. The heat transferred by liquid water at the bottom layer $\left(q_{\mathrm{L}, 17}\right)$ is zero. $\theta$, volumetric soil moisture $\left(\mathrm{m}^{3} \mathrm{~m}^{-3}\right) ; q_{\mathrm{L}}$, liquid water flux $\left(\mathrm{m} \mathrm{s}^{-1}\right), q_{\mathrm{L}, \mathrm{k}}=-0.5 \times\left(D\left(\theta_{k-1}\right)+D\left(\theta_{k}\right)\right) \times\left(\theta_{k}-\theta_{k-1}\right) / \Delta z_{k}+0.5 \times\left(K\left(\theta_{k-1}\right)+K\left(\theta_{k}\right)\right) ; D$, hydraulic diffusivity (m $\left.{ }^{2} \mathrm{~s}^{-1}\right) ; K, \mathrm{hydraulic}$ conductivity $\left(\mathrm{m} \mathrm{s}^{-1}\right)$; $u s$, water uptake due to transpiration (no transpiration at the top layer); $T$, soil temperature (K); $G$ : soil heat flux $\left(\mathrm{W} \mathrm{m}^{-2}\right) ; z z, z l$ : soil depth at node and interface, respectively $(\mathrm{m}) ; \Delta z$, thickness of each layer $(\mathrm{m})$; $C_{\mathrm{P}}$, soil volumetric heat capacity $\left(\mathrm{J} \mathrm{m}^{-3} \mathrm{~K}^{-1}\right) ; \lambda$, soil thermal conductivity $\left(\mathrm{W} \mathrm{m}^{-1} \mathrm{~K}^{-1}\right)$.
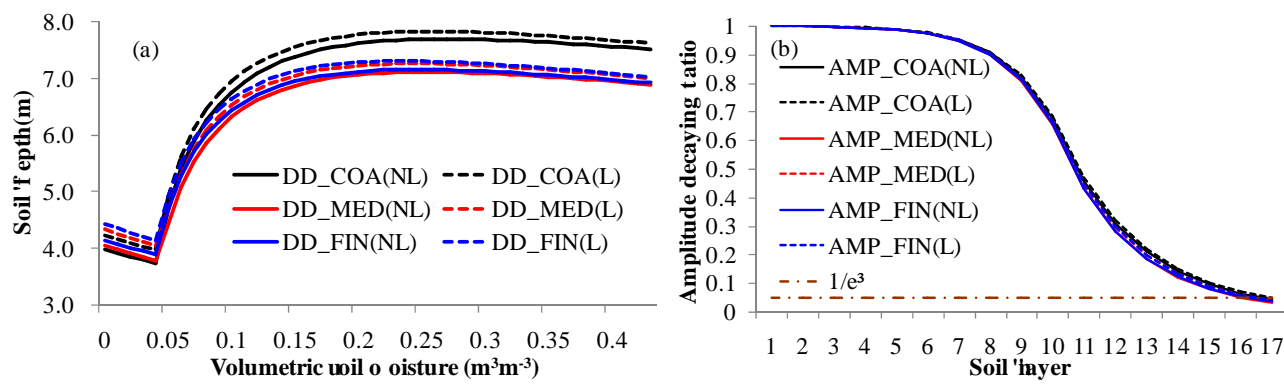

Figure 3. The variation of required soil depth for simulating annual cycles of soil temperature / heat flux with volumetric soil moisture (a), and the variation of soil temperature / heat flux amplitude decaying ratio with soil layers (b) for different soil textures: coarse (COA), medium (MED), and fine (FIN). The soil heat convection by liquid water transport ( $\left.8.64 \mathrm{~mm} \mathrm{~d}^{-1}\right)$ is considered in "L" (dashed line), and it is excluded in "NL" (solid line). The black, red, and blue lines represent coarse, medium, and fine soils, respectively.

Figure $3 \mathrm{a}$ shows the variation of $\mathrm{DD}_{y}$ with the volumetric soil moisture for three different soil textures (i.e. coarse, medium, and fine). $\mathrm{DD}_{y}$ varies with the soil texture because a larger depth $(\sim 8 \mathrm{~m})$ is necessary for coarser textures. $\mathrm{DD}_{y}$ increases when the soil heat convection process is considered (with $q_{\mathrm{L}}$ set to a medium value $1.0 \times 10^{-7} \mathrm{~m} \mathrm{~s}^{-1}$, $8.64 \mathrm{~mm} \mathrm{~d}^{-1}$; dashed line in Fig. 3a). For the coarse soil and when the soil heat convection is considered (black dashed line in Fig. 3a), the maximum $\mathrm{DD}_{y}$ is around $8 \mathrm{~m}$. Figure $3 \mathrm{~b}$ shows the variation of the soil temperature/heat flux amplitude decay ratio (i.e. the ratio of the amplitude of the bottom variation and the amplitude of the surface variation) with the soil depth. The deeper the soil, the larger the decay of the amplitude of the soil temperature/heat flux. In the bottom 
Table 3. The soil vertical discretizations of 5M7L, 2M11L, and 8M17L.

\begin{tabular}{|c|c|c|c|c|c|c|}
\hline \multirow[b]{2}{*}{ Layer } & \multicolumn{2}{|c|}{$5 \mathrm{M} 7 \mathrm{~L}$} & \multicolumn{2}{|c|}{$2 \mathrm{M} 11 \mathrm{~L}$} & \multicolumn{2}{|c|}{$8 \mathrm{M} 17 \mathrm{~L}$} \\
\hline & $z z(\mathrm{~m})$ & $z l(\mathrm{~m})$ & $z z(\mathrm{~m})$ & $z l(\mathrm{~m})$ & $z z(\mathrm{~m})$ & $z l(\mathrm{~m})$ \\
\hline 1 & $1.419 \times 10^{-2}$ & $3.426 \times 10^{-2}$ & 0 & $0.978 \times 10^{-3}$ & $0 / 0.489 \times 10^{-3 *}$ & $0.978 \times 10^{-3}$ \\
\hline 2 & $6.264 \times 10^{-2}$ & $1.028 \times 10^{-1}$ & $1.955 \times 10^{-3}$ & $3.910 \times 10^{-3}$ & $1.955 \times 10^{-3}$ & $3.910 \times 10^{-3}$ \\
\hline 3 & $1.595 \times 10^{-1}$ & $2.398 \times 10^{-1}$ & $5.865 \times 10^{-3}$ & $9.775 \times 10^{-3}$ & $5.865 \times 10^{-3}$ & $9.775 \times 10^{-3}$ \\
\hline 4 & $3.533 \times 10^{-1}$ & $5.139 \times 10^{-1}$ & $1.369 \times 10^{-2}$ & $2.151 \times 10^{-2}$ & $1.369 \times 10^{-2}$ & $2.151 \times 10^{-2}$ \\
\hline 5 & $7.409 \times 10^{-1}$ & 1.062 & $2.933 \times 10^{-2}$ & $4.497 \times 10^{-2}$ & $2.933 \times 10^{-2}$ & $4.497 \times 10^{-2}$ \\
\hline 6 & 1.516 & 2.158 & $6.061 \times 10^{-2}$ & $9.189 \times 10^{-2}$ & $6.061 \times 10^{-2}$ & $9.189 \times 10^{-2}$ \\
\hline 7 & 3.066 & 4.351 & $1.232 \times 10^{-1}$ & $1.857 \times 10^{-1}$ & $1.232 \times 10^{-1}$ & $1.857 \times 10^{-1}$ \\
\hline 8 & & & $2.483 \times 10^{-1}$ & $3.734 \times 10^{-1}$ & $2.483 \times 10^{-1}$ & $3.734 \times 10^{-1}$ \\
\hline 9 & & & $4.985 \times 10^{-1}$ & $7.488 \times 10^{-1}$ & $4.985 \times 10^{-1}$ & $7.488 \times 10^{-1}$ \\
\hline 10 & & & $9.990 \times 10^{-1}$ & 1.500 & $9.990 \times 10^{-1}$ & 1.500 \\
\hline 11 & & & 2.000 & 2.000 & 2.000 & 2.500 \\
\hline 12 & & & & & 3.001 & 3.501 \\
\hline 13 & & & & & 4.002 & 4.502 \\
\hline 14 & & & & & 5.003 & 5.503 \\
\hline 15 & & & & & 6.004 & 6.504 \\
\hline 16 & & & & & 7.005 & 7.505 \\
\hline 17 & & & & & $8.006 / 7.755^{*}$ & 8.006 \\
\hline
\end{tabular}

$z z$ : the depth at discretized node; $z l$ : the depth at layer interface. ${ }^{*} 0$ and $8.006 \mathrm{~m}$ for hydrology model, $0.489 \times 10^{-3}$ and $7.755 \mathrm{~m}$ for thermal model.

layer, the amplitude decay ratio for the soil temperature and the heat flux go to less than $e^{-3}$. The soil depth is therefore chosen to be $8 \mathrm{~m}$, which corresponds to 17 layers according to the criteria previously described (Fig. 2c, Table 3, Appendix B).

The soil thermodynamics model with the proposed vertical discretization $(8 \mathrm{M} 17 \mathrm{~L})$ is evaluated in a 1-D framework. The FDM numerical solution is compared with the analytical solution for the diurnal and the annual cycle and for a steady water flow. $C_{\mathrm{P}}\left(2.135 \times 10^{6} \mathrm{~J} \mathrm{~m}^{-3} \mathrm{~K}^{-1}\right)$ and $\lambda$ $\left(1.329 \mathrm{~W} \mathrm{~m}^{-1} \mathrm{~K}^{-1}\right)$ are set to constant values. To ensure numerical robustness and accuracy, a quite large value of steady water flow $q_{\mathrm{L}}$ is chosen $\left(1.0 \times 10^{-7} \mathrm{~m} \mathrm{~s}^{-1}, 8.64 \mathrm{~mm} \mathrm{~d}^{-1}\right.$, $3153.6 \mathrm{~mm} \mathrm{yr}^{-1}$ ). Figure $4 \mathrm{a}$ and $\mathrm{c}$ show the soil temperature and soil heat flux in the first and in the 17 layers (i.e. 16 layer for heat flux). The time series of the soil temperature and the soil heat flux for the FDM are in good agreement with the analytical solutions. The vertical profiles of daily soil temperature $(T)$ and soil heat flux $(G)$ simulated with the FDM are close to the analytical solution as well (Fig. 4b and d). The soil temperature and the soil heat flux are almost constant in the bottom layer as required by the zero flux assumption. The results are robust when changing the amplitude of the external forcing (not shown).

\section{Evaluation of the revised soil thermodynamics scheme in a coupled atmosphere-land model}

\subsection{The evaluation approach}

When evaluating new parameterizations in a climate model, a challenge is to isolate the effects of the modified parameterizations from the model internal variability, especially when the signal is weak. The traditional way of doing this is to run paired experiments (with and without modification) under unconstrained meteorology over decades or hundreds of years (Forster and Taylor, 2006). This traditional approach requires long computing time to simulate the full range of climate variability (Kooperman et al., 2012). A way to reduce the internal variability is to constrain the large-scale atmosphere dynamics towards prescribed atmospheric conditions using a nudging approach (Coindreau et al., 2007). This method has been successfully used to evaluate the parameterizations related to the land-surface-atmosphere coupling (e.g. Cheruy et al., 2013). The simulated wind fields (zonal $u$; meridional $v$ ) are relaxed towards the ECMWF reanalyzed winds with a $6 \mathrm{~h}$ relaxing time ( $\tau_{\text {nudge }}$ ) by adding a relaxation term to the model equations

$\frac{\partial X}{\partial t}=F(X)+\frac{X^{\mathrm{a}}-X}{\tau_{\text {nudge }}}$,

where $X$ is $u$ or $v, F$ is the operator describing the dynamical and physical processes that determine the evolution of $X$, and $X^{\mathrm{a}}$ is the analyzed field of ECMWF.

Several experiments are performed to evaluate step by step the impact of the various modifications. $\mathrm{EXP}_{8 \mathrm{~m}}$ is designed 

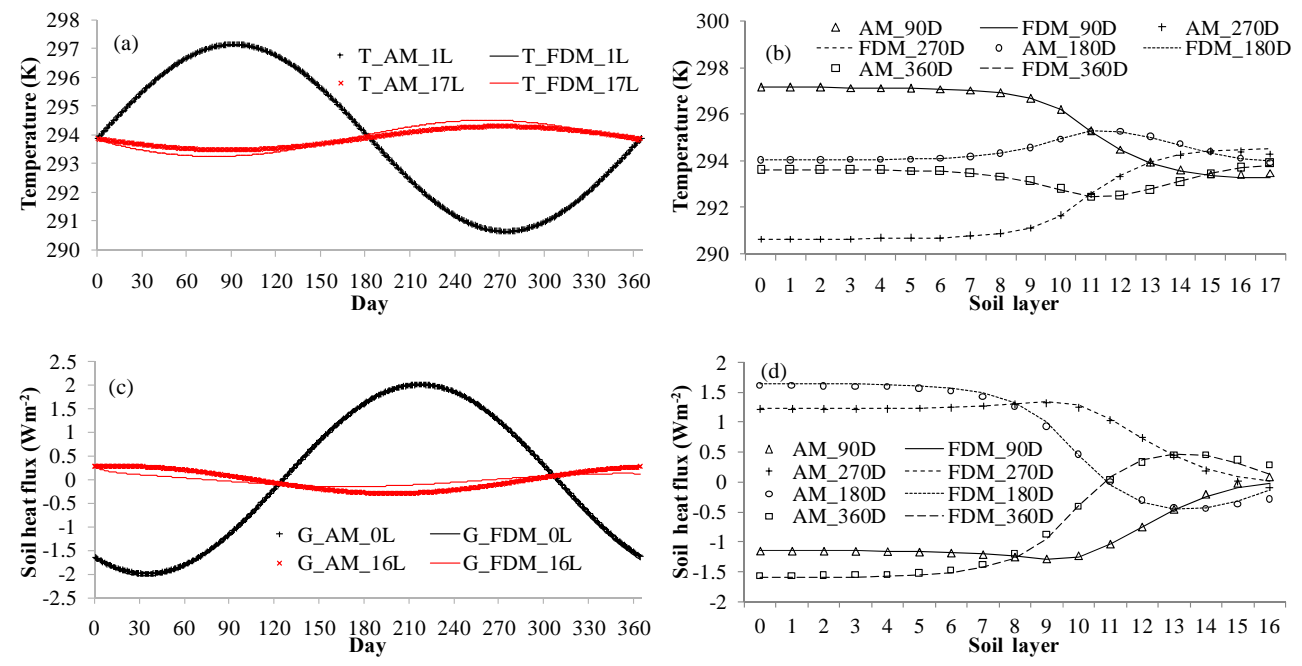

Figure 4. The comparison of daily soil temperature ( $T, \mathbf{a}$ and $\mathbf{b})$ and soil heat flux $(G, \mathbf{c}$ and $\mathbf{d})$ between analytical method (AM) and finite difference method $(\mathrm{FDM})$ for soil heat conduction-convection model by using $8 \mathrm{M} 17 \mathrm{~L}$ discretization with liquid water flux $q_{\mathrm{L}}=$ $1 \times 10^{-7} \mathrm{~m} \mathrm{~s}^{-1}\left(8.6 \mathrm{~mm} \mathrm{~d}^{-1}\right)$ : time serials (a, c) and vertical profiles (b, d). The black lines and red lines in (a) plot the values at the first layer $(1 \mathrm{~L})$ and at the 17 th layer $(17 \mathrm{~L})$, respectively. The black lines and red lines in (c) plot the values at the surface $(0 \mathrm{~L})$ and at the 16 th layer (16L), respectively. The symbols $\triangle,+, \bigcirc, \square$ in (b) and (d) correspond to AM values at 90th day (90D), 270th day (270D), 180th

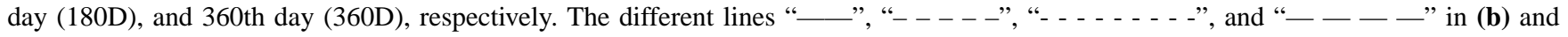
(d) correspond to FDM values at 90D, 270D, 180D, and 360D, respectively.

with the "8M17L" discretization, a constant soil thermal conductivity $\left(1.329 \mathrm{~W} \mathrm{~m}^{-1} \mathrm{~K}^{-1}\right)$ and heat capacity $(2.135 \times$ $10^{6} \mathrm{~J} \mathrm{~m}^{-3} \mathrm{~K}^{-1}$ ), which are typical of intermediate soil moisture conditions $\left(0.21 \mathrm{~m}^{3} \mathrm{~m}^{-3}\right)$. $\operatorname{EXP}_{8 \mathrm{~m}}$ is used as a control experiment. Three sensitivity experiments (EXPs) are designed to individually test the impact of the soil depth/vertical discretization, the energy transfer by the liquid water, and the parameterization of soil thermal properties. The differences between the experiments are mapped only when the modification is statistically significant ( $t$ test), otherwise the pixels are left blank. For all experiments, a 7 year spin-up is performed in order for the temperature to reach equilibrium. This spin-up period might be short over some regions for the moisture in the deep soil layers. However, the global soil temperature was shown to have reached equilibrium in all experiments after 7 years.

\subsection{The soil vertical discretization and soil depth with constant soil thermal properties}

To test the vertical discretization and the soil depth $\mathrm{EXP}_{5 \mathrm{~m}}$ is designed to be identical to the $\mathrm{EXP}_{8 \mathrm{~m}}$ except for the soil vertical discretization, which is replaced by the standard one (Table 4). Figure 5 shows the annual average volumetric soil moisture $(0-1.5 \mathrm{~m})$, the surface temperature, the sensible heat flux, the latent heat flux, the total runoff and the precipitation for $\mathrm{EXP}_{8 \mathrm{~m}}$, as well as the difference between $\mathrm{EXP}_{8 \mathrm{~m}}$ and $\mathrm{EXP}_{5 \mathrm{~m}}$. The high-latitude regions of the Northern Hemisphere $\left(60-90^{\circ} \mathrm{N}\right)$ are not considered since the surface thermal properties are modified by the snow thermal properties, whose description is beyond the scope of this paper. The differences of volumetric soil moisture between 0 and $1.5 \mathrm{~m}$ between $\operatorname{EXP}_{8 \mathrm{~m}}$ and $\mathrm{EXP}_{5 \mathrm{~m}}$ are less than $0.05 \mathrm{~m}^{3} \mathrm{~m}^{-3}$ with the largest difference in the tropical humid regions (e.g., over the Congo Basin and Amazonia, Fig. 5b). The impact of soil vertical discretization on the surface temperature and on the turbulent fluxes is almost negligible everywhere except over very humid regions, such as Brazil, where the differences can reach $0.5-1 \mathrm{~K}$ for the temperature (Fig. $5 \mathrm{c}$ and d) and $10-15 \mathrm{~W} \mathrm{~m}^{-2}$ for the turbulent fluxes (Fig. 5e-h). One possible cause for this difference could be the insufficient soil depth in $\operatorname{EXP}_{5 \mathrm{~m}}$ (5 $\mathrm{m}$ for temperature) for simulating the soil temperature annual cycles. Another possible contribution comes from the increase of total runoff ( $\mathrm{R}_{\mathrm{OFF}, \mathrm{TOT}}$; the sum of surface runoff and deep drainage) over tropical humid regions (Fig. 5i-j) for $\mathrm{EXP}_{5 \mathrm{~m}}$ (2M11L for moisture) due to the slightly change of hydraulic conductivity vertical profile. The hydraulic conductivity at the surface for $\mathrm{EXP}_{5 \mathrm{~m}}$ is smaller than $\mathrm{EXP}_{8 \mathrm{~m}}$, and it prevents more water from penetrating into the soil. At the bottom layer, the hydraulic conductivity for $\operatorname{EXP}_{5 \mathrm{~m}}$ (at $2 \mathrm{~m}$ ) is higher than $\operatorname{EXP}_{8 \mathrm{~m}}$ (at $8 \mathrm{~m}$ ), and it generates more drainage in $\mathrm{EXP}_{5 \mathrm{~m}}$. This variation also induces a decrease of soil moisture (e.g., at 1st layer) in $\mathrm{EXP}_{5 \mathrm{~m}}$ comparing with $\mathrm{EXP}_{8 \mathrm{~m}}$. The near-surface air humidity is also decreased over these regions following the change of surface moisture, and it corresponds to smaller precipitation and evaporation in $\mathrm{EXP}_{5 \mathrm{~m}}$ than in $\mathrm{EXP}_{8 \mathrm{~m}}$ (Fig. 5k-1). Previous studies also find that the deeper soil depth leads to a higher soil moisture (Decharme et al., 2013). In Brazil and central 


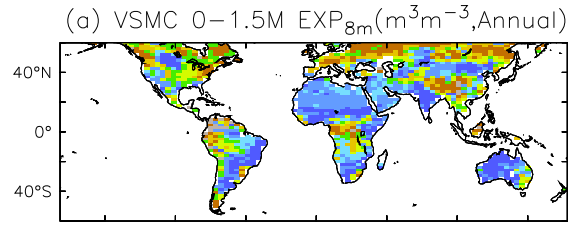

(c) $T_{S} \operatorname{EXP}_{8 m}(K$, Annual)

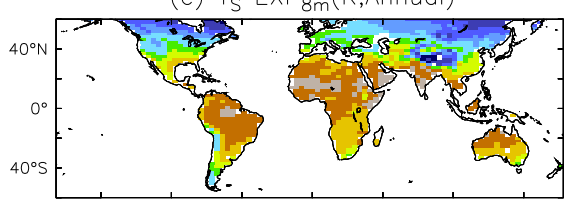

(e) $F_{1}{ }^{h} \operatorname{EXP}_{8 m}\left(W^{-2}\right.$,Annual $)$

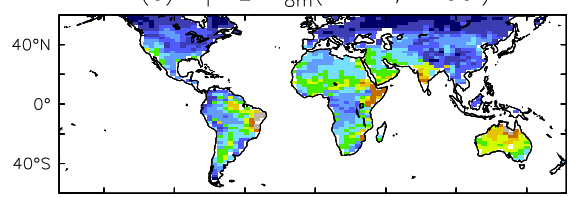

(g) $L F_{1}{ }^{q} \operatorname{EXP}_{8 m}\left(W^{-2}\right.$, Annual $)$

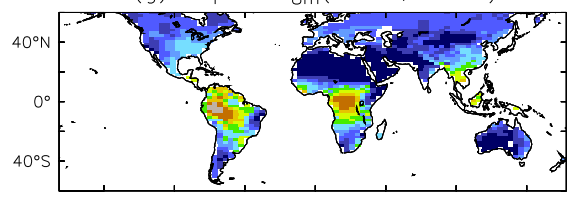

(i) $R_{\text {OFF,TOT }} \operatorname{EXP}_{8 m}\left(\mathrm{~mm} \mathrm{~d}^{-1}\right.$,Annual)

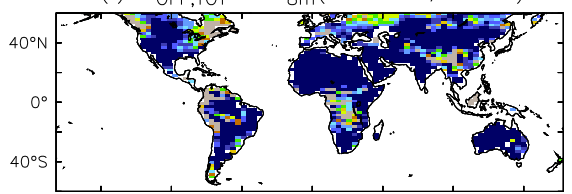

(k) $P \operatorname{EXP}_{8 m}\left(m m d^{-1}\right.$,Annual)

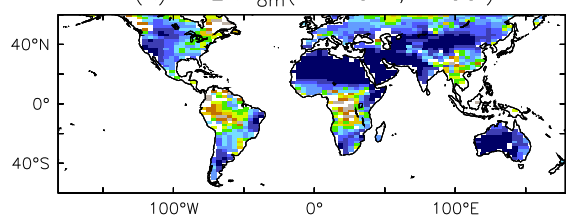

(b) VSMC $0-1.5 \mathrm{M} \operatorname{EXP}_{5 m}-\operatorname{EXP}_{8 m}\left(\mathrm{~m}^{3} \mathrm{~m}^{-3}\right.$, Annual)

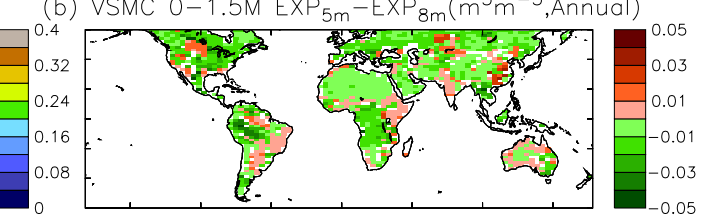

(d) $T_{S} \operatorname{EXP}_{5 m}-\operatorname{EXP}_{8 m}(K$, Annual)

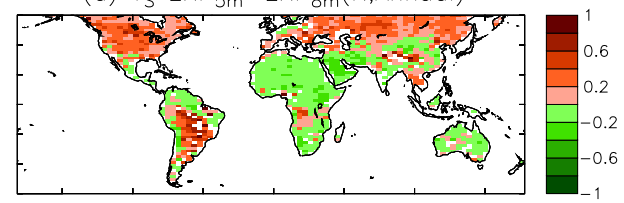

(f) $F_{1}{ }^{h} \operatorname{EXP}_{5 m}-\operatorname{EXP}_{8 m}\left(W^{-2}\right.$,Annual)

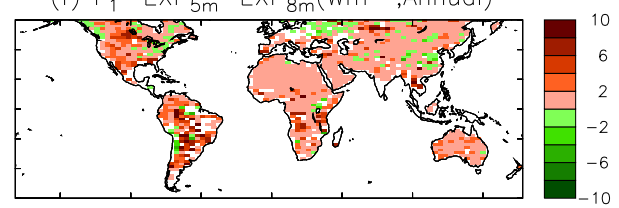

(h) $L F_{1}{ }^{q} \operatorname{EXP}_{5 m}-\operatorname{EXP}_{8 m}\left(W_{m}^{-2}\right.$,Annual)

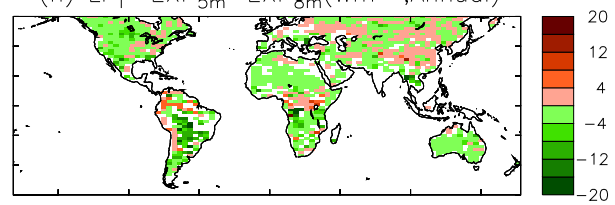

(j) $R_{\text {OFF,TOT }}\left(\operatorname{EXP}_{5 m}-E_{8 P_{8 m}}\right)\left(m m d^{-1}\right.$,Annual)

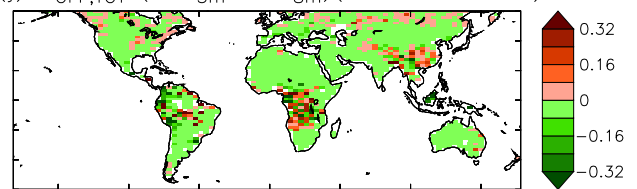

(1) $P \operatorname{EXP}_{5 m}-\operatorname{EXP}_{8 m}\left(m m d^{-1}\right.$,Annual)

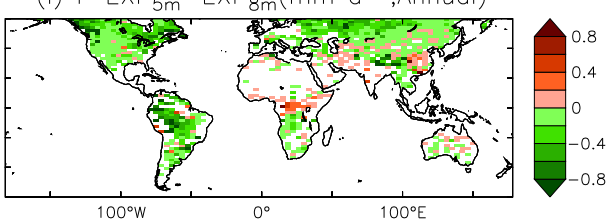

Figure 5. The results of $\operatorname{EXP}_{8 \mathrm{~m}}\left(8 \mathrm{M} 17 \mathrm{~L}\right.$, left) and the difference between $\operatorname{EXP}_{5 \mathrm{~m}}\left(5 \mathrm{M} 7 \mathrm{~L}\right.$, Table 4) and $\mathrm{EXP}_{8 \mathrm{~m}}($ right $)$ : (a, b) volumetric soil moisture content at $0-1.5 \mathrm{~m},(\mathbf{c}, \mathbf{d})$ surface temperature $T_{\mathrm{S}},(\mathbf{e}, \mathbf{f})$ sensible heat flux $F_{1}^{\mathrm{h}},(\mathbf{g}, \mathbf{h})$ latent heat flux $\mathrm{LF}_{1}^{q}$, (i, $\left.\mathbf{j}\right)$ total runoff $R_{\mathrm{OFF}, \mathrm{TOT}}$, and (k, l) precipitation $P$.

Table 4. The parameterization settings and evaluations for LMDZOR 3-D experiments.

\begin{tabular}{|c|c|c|c|c|c|c|}
\hline \multirow[t]{2}{*}{ Name } & \multicolumn{5}{|c|}{ The experiments setup } & \multirow{2}{*}{$\begin{array}{l}\text { The evaluations } \\
\text { The variables compared }\end{array}$} \\
\hline & $\begin{array}{r}\text { Length } \\
\text { (year) }\end{array}$ & $\begin{array}{l}\text { Vertical } \\
\text { layer }\end{array}$ & $\begin{array}{l}\text { Soil heat } \\
\text { convection }\end{array}$ & $\begin{array}{l}\text { Soil thermal } \\
\text { conductivity }(\lambda)\end{array}$ & $\begin{array}{l}\text { Soil heat } \\
\text { capacity }\left(C_{\mathrm{P}}\right)\end{array}$ & \\
\hline $\mathrm{EXP}_{8 \mathrm{~m}}$ & 20 & $8 \mathrm{M} 17 \mathrm{~L}$ & No & $1.329 \mathrm{~W} \mathrm{~m}^{-1} \mathrm{~K}^{-1}$ & $2.135 \times 10^{6} \mathrm{~J} \mathrm{~m}^{-3} \mathrm{~K}^{-1}$ & - \\
\hline $\mathrm{EXP}_{5 \mathrm{~m}}$ & 20 & $5 \mathrm{M} 7 \mathrm{~L}$ & No & $1.329 \mathrm{~W} \mathrm{~m}^{-1} \mathrm{~K}^{-1}$ & $2.135 \times 10^{6} \mathrm{~J} \mathrm{~m}^{-3} \mathrm{~K}^{-1}$ & $\mathrm{VSMC}, T_{\mathrm{S}}, F_{1}^{\mathrm{h}}, \mathrm{LF}_{1}^{q}, R_{\mathrm{OFF}, \mathrm{TOT}}, P$ \\
\hline $\mathrm{EXP}_{8 \mathrm{~m}, \mathrm{LT}}$ & 20 & $8 \mathrm{M} 17 \mathrm{~L}$ & Yes & $1.329 \mathrm{~W} \mathrm{~m}^{-1} \mathrm{~K}^{-1}$ & $2.135 \times 10^{6} \mathrm{~J} \mathrm{~m}^{-3} \mathrm{~K}^{-1}$ & $q_{\mathrm{L}, 0}, T_{\mathrm{rain}}-T_{\mathrm{S}}, H_{1}, T_{\mathrm{S}}$ \\
\hline $\mathrm{EXP}_{8 \mathrm{~m}, \mathrm{LT}, \mathrm{TP}}$ & 20 & $8 \mathrm{M} 17 \mathrm{~L}$ & Yes & $\mathrm{J} 75$ & $\mathrm{P} 02$ & $\begin{array}{l}\lambda, C_{\mathrm{P}}, K_{T}, I, T_{\mathrm{S}}, T_{2 \mathrm{~m}, \max }, T_{2 \mathrm{~m}, \min }, \\
\mathrm{LF}_{1}^{q}, F_{1}^{\mathrm{h}}, \mathrm{DTR}, \mathrm{ETR}, \mathrm{ITV}, \mathrm{IT}_{\mathrm{N}} \mathrm{V}\end{array}$ \\
\hline
\end{tabular}

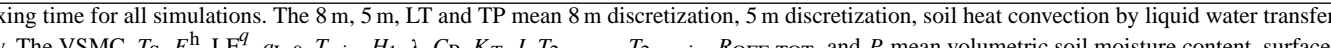
temperature, sensible heat flux, latent heat flux, water flux at surface, rain temperature, rain heat flux, soil thermal conductivity, soil heat capacity, soil heat diffusivity, soil thermal inertia, daily maximum air temperature, daily minimum air temperature, total runoff, and precipitation. The DTR, ETR, ITV, and IT $\mathrm{N}_{\mathrm{V}}$ mean diurnal temperature range, intra-annual extreme temperature range, inter-diurnal temperature variability of the daily mean (ITV) and of the minimum temperature (IT $\mathrm{N}_{\mathrm{V}}$ ). 

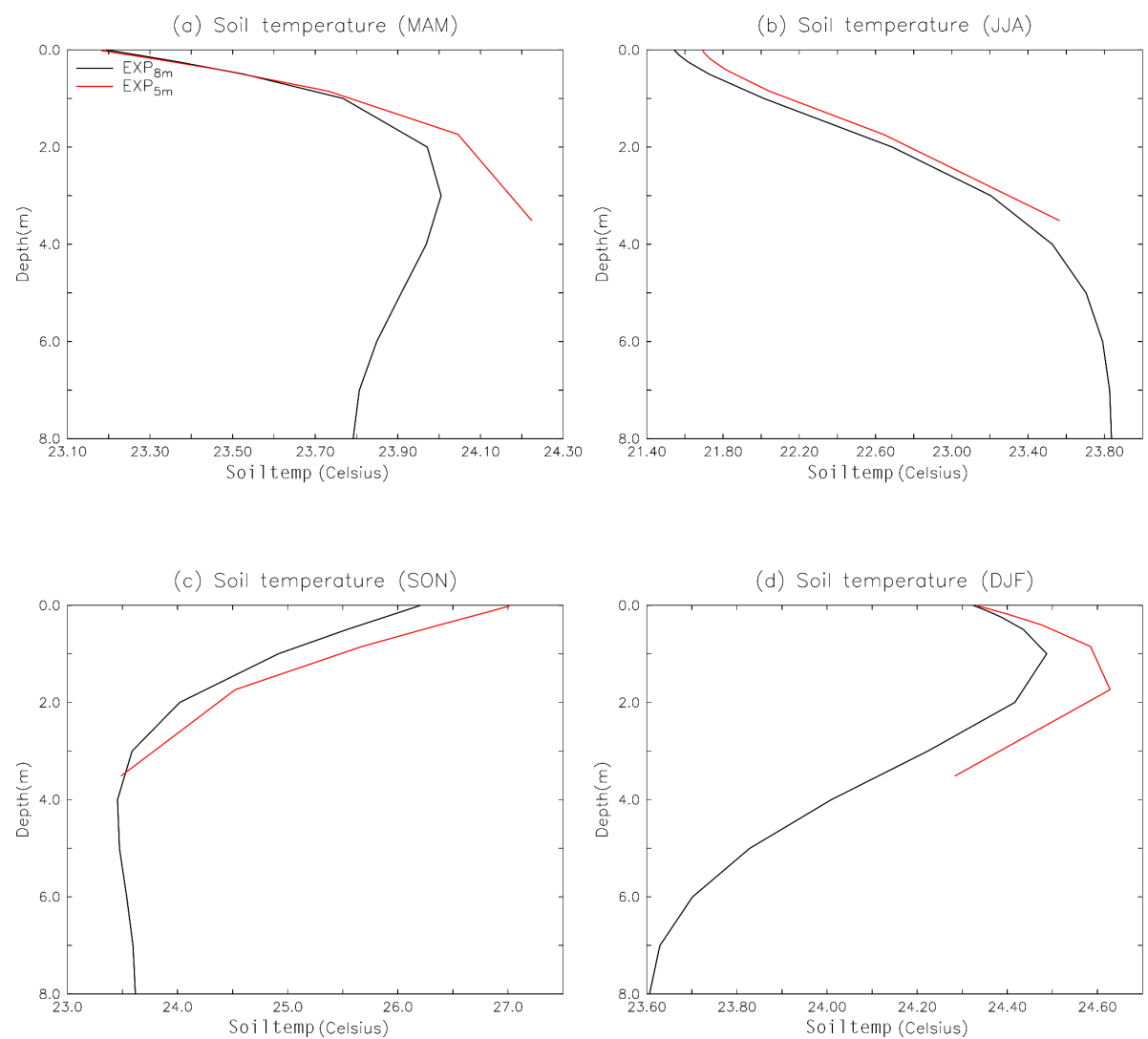

Figure 6. The vertical profiles of soil temperature in March-April-May (MAM) (a), June-July-August (JJA) (b), September-OctoberNovember (SON) (c), and December-January-February (DJF) (d) over Brazil (50-70 W, 5-20 ${ }^{\circ}$ S) for 8M17L (EXP $8 \mathrm{~m}$, black line) and 5M7L $\left(\mathrm{EXP}_{5 \mathrm{~m}}\right.$, red line) vertical discretizations.

Africa, there are more intense rain events, and the impact is larger over these regions.

Figure 6 shows the vertical profiles of soil temperature in a region centered on Brazil $\left(50-70^{\circ} \mathrm{W}, 20-5^{\circ} \mathrm{S}\right)$ for $\mathrm{EXP}_{8 \mathrm{~m}}$ (black line) and $\mathrm{EXP}_{5 \mathrm{~m}}$ (red line) and for the four seasons. In June-July-August (JJA), the soil temperature increases with soil depth, releasing heat (Fig. 6b) whereas the soil temperature decreases with soil depth, absorbing heat, in SeptemberOctober-November (SON) (Fig. 6c). In the deepest soil layer, the annual amplitude of the soil temperature for $\mathrm{EXP}_{5 \mathrm{~m}}$ $(0.8 \mathrm{~K}, \sim 15 \%$ of the surface temperature) is much larger than that for $\operatorname{EXP}_{8 \mathrm{~m}}(0.15 \mathrm{~K}, \sim 3 \%$ of the surface temperature) and the gradient of the bottom soil temperature for $\mathrm{EXP}_{5 \mathrm{~m}}$ is much higher than that for $\mathrm{EXP}_{8 \mathrm{~m}}$. These results show that in very moist regions, an $8 \mathrm{~m}$ depth is needed for the zero-flux condition to be satisfied.

\subsection{The effects of the rainfall heat flux at the surface}

The difference between the temperature of the rain reaching the surface and the temperature of the surface itself during rainy events induces a sensible heat flux. Together with the energy transported by liquid water into the soil, this sensi- ble heat flux impacts the energy budget. These two processes have been included in the soil thermodynamics scheme and their effect on the near-surface variables is evaluated by comparing $\mathrm{EXP}_{8 \mathrm{~m}}$ and $\mathrm{EXP}_{8 \mathrm{~m}, \mathrm{LT}}$ (Table 4). The latter is identical to $\mathrm{EXP}_{8 \mathrm{~m}}$ but with the parameterization of the abovementioned processes activated. Figure $7 \mathrm{a}$ shows the 20 year annual mean rain water flux ( $q_{\mathrm{L}, 0}$ in Eq. 3 ) at the surface. This flux is maximum in tropical regions (approximately 3 $5 \mathrm{~mm} \mathrm{~d}^{-1}$ ) because of the higher rainfall in these regions, corresponding to -0.5 to $-0.75 \mathrm{~W} \mathrm{~m}^{-2}$ rainwater heat flux $\left(H_{1}\right.$ in Eqs. 2 and 3; $H_{1}$ depends on $q_{\mathrm{L}, 0}$ and the temperature gradient of rainfall and surface). The overall effect on the temperature is very weak and results in a slight cooling (less than $0.3 \mathrm{~K}$, Fig. $7 \mathrm{~d}$ ) because the rainfall is colder than the soil surface (Fig. $7 \mathrm{~b}$ ). The negative $H_{1}$ reduces the net energy at surface, and the surface temperature decreases based on surface energy budget (Eq. 2). The impact of the energy transported by the liquid water into the sub-surface $\left(-C_{\mathrm{W}} \frac{\partial q_{\mathrm{L}} T}{\partial z}-C_{\mathrm{W}} \mathrm{ST}\right.$ in Eq. 1) is even weaker than the rainwater heat flux at the surface (not shown). 


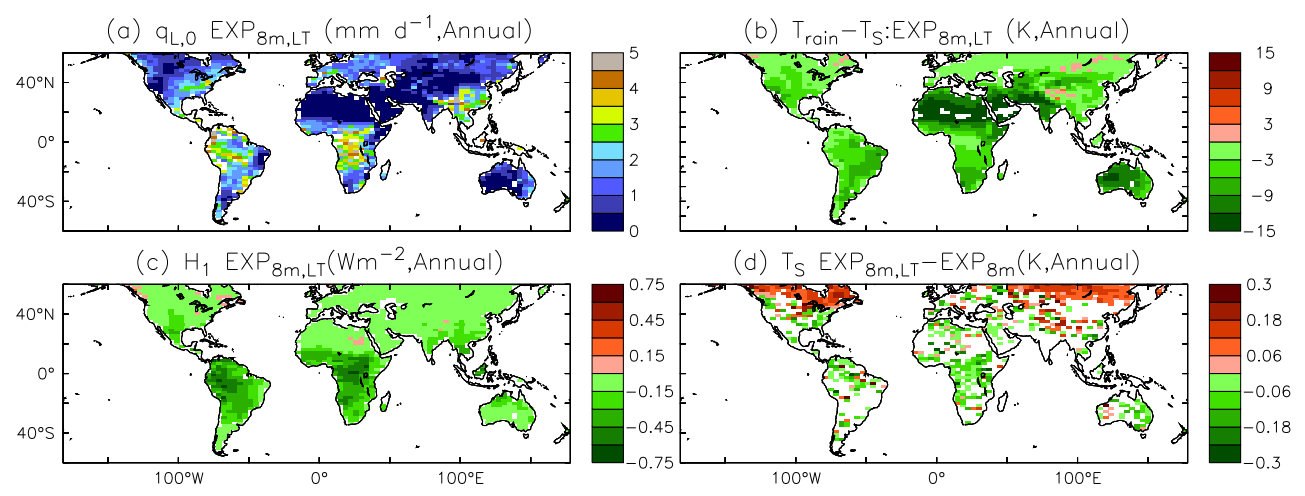

Figure 7. (a) Liquid water flux at surface, (b) difference between rain and surface temperature, (c) heat fluxes by convection at surface for EXP $_{8 \mathrm{~m}, \mathrm{LT}}$ (Table 4), and (d) differences in surface temperature due to the heat transferred by rain and water into the soil (differences between $\mathrm{EXP}_{8 \mathrm{~m}, \mathrm{LT}}$ and $\left.\mathrm{EXP}_{8 \mathrm{~m}}\right)$. All values are annual mean.

\subsection{Evaluation of the full soil thermodynamics scheme}

The experiment $\mathrm{EXP}_{8 \mathrm{~m}, \mathrm{LT}, \mathrm{TP}}$ where the full scheme is implemented (e.g. new vertical discretization and depth, soil heat convection process and new soil thermal properties; Table 4) is now compared with the reference experiment $\mathrm{EXP}_{8 \mathrm{~m}}$ where only the new vertical discretization and depth are implemented. The soil thermal conductivity, soil heat capacity, and soil thermal inertia decrease (increase, respectively) over arid (humid, respectively) regions as a result of the texture and the moisture dependence of the soil thermal property (Fig. 8a-c). The soil thermal property in $\mathrm{EXP}_{8 \mathrm{~m}}$ $\left(1.329 \mathrm{~W} \mathrm{~m}^{-1} \mathrm{~K}^{-1}\right)$ and $\left.2.135 \times 10^{6} \mathrm{~J} \mathrm{~m}^{-3} \mathrm{~K}^{-1}\right)$ is obtained from an averaged moisture $\left(0.21 \mathrm{~m}^{3} \mathrm{~m}^{-3}\right)$. The wetter (drier) the regions are, the larger the increase (decrease) of soil thermal property for $\mathrm{EXP}_{8 \mathrm{~m}, \mathrm{LT}, \mathrm{TP}}$. A lower thermal inertia corresponds to lower heat storage ability in the soil. The soil heat diffusivity decreases over the whole globe with large decreases over arid areas such as Sahara, west Australia, South Africa, and South America (Fig. 8d). The downwards energy transport from the heated surface during the day is slower with a smaller heat diffusivity, but less heat is transferred towards the surface to compensate the radiative cooling during the night. However, the effect is larger during the night than during the day: the daily maximum air temperature increases by $\sim 0-1 \mathrm{~K}$ (Fig. $8 \mathrm{~g}$ and $\mathrm{h}$ ) while the daily minimum air temperature decreases by $\sim 1-5 \mathrm{~K}$ over more than $50 \%$ of the regions (Fig. 8i and j), resulting in a net cooling. This is mainly because the turbulent transfer is stronger during the day than during the night, and the impacts on daily maximum temperature are compensated by the turbulent flux. These results were analyzed by Ait Mesbah et al. (2015). From the energy point of view, the surface cooling induces a net radiation increase due to a decreased radiative cooling. This net radiation increase is compensated by an increased sensible heat flux (Fig. 8m and n). The effect of the soil thermal properties is stronger during the dry season over the Sahara (20-35 $\mathrm{E}, 10-35^{\circ} \mathrm{N}$; not shown). Both the soil heat capacity and thermal conductivity decrease over the Sahara region due to the low soil moisture (see Fig. 1). The lower soil thermal inertia also induces $\mathrm{a} \sim 20-30 \mathrm{~W} \mathrm{~m}^{-2}$ decrease of the diurnal amplitude of the ground heat flux over the Sahara (not shown). The change in latent heat flux (around $\pm 2 \mathrm{~W} \mathrm{~m}^{-2}$ ) is much less than sensible heat flux (around $\pm 6 \mathrm{~W} \mathrm{~m}^{-2}$ ) for most regions (Fig. 8k and 1). This is reasonable because the moisture between the two experiments does not change significantly (both experiments use 8M17L discretization); thus, the variation of latent heat flux (water cycle) is small.

\section{The impact of the soil thermodynamics on the temperature variability}

The new soil thermodynamics induces an overall increase of the mean diurnal temperature range (DTR; the difference between the daily maximum temperature and the daily minimum temperature) and the intra-annual extreme temperature range (ETR; the difference between the highest temperature of 1 year and the lowest temperature of the same year) due to an increase of daily maximum temperature and a decrease of daily minimum temperature (Fig. $8 \mathrm{~h}$ and j). DTR increases by 1 to $3 \mathrm{~K}$ over $\sim 60 \%$ of the regions and $4 \mathrm{~K}$ over $5 \%$ of the regions (Fig. 9a and $\mathrm{b}$ ) and ETR increases by $1-4 \mathrm{~K}$ over $\sim 60 \%$ of the regions and $5-6 \mathrm{~K}$ over $8 \%$ of the regions (Fig. 9c and d), respectively. The impact of the new soil thermodynamics is strong over arid and semi-arid areas (due to the change of soil thermal property by soil moisture and soil texture effects) but also over mid-latitude regions such as the central North America and in particular over the southern Great Plains, where the soil-moisture-atmosphere coupling plays a significant role (Koster et al., 2004). These results show that the parameterization of the soil thermal properties has a significant impact on the temperature on the daily to annual timescale. Together with the evaporative fraction and the cloud radiative properties (e.g. Cheruy et al., 2014; Lindvall and Svenson, 2014), the parameterization of the soil 

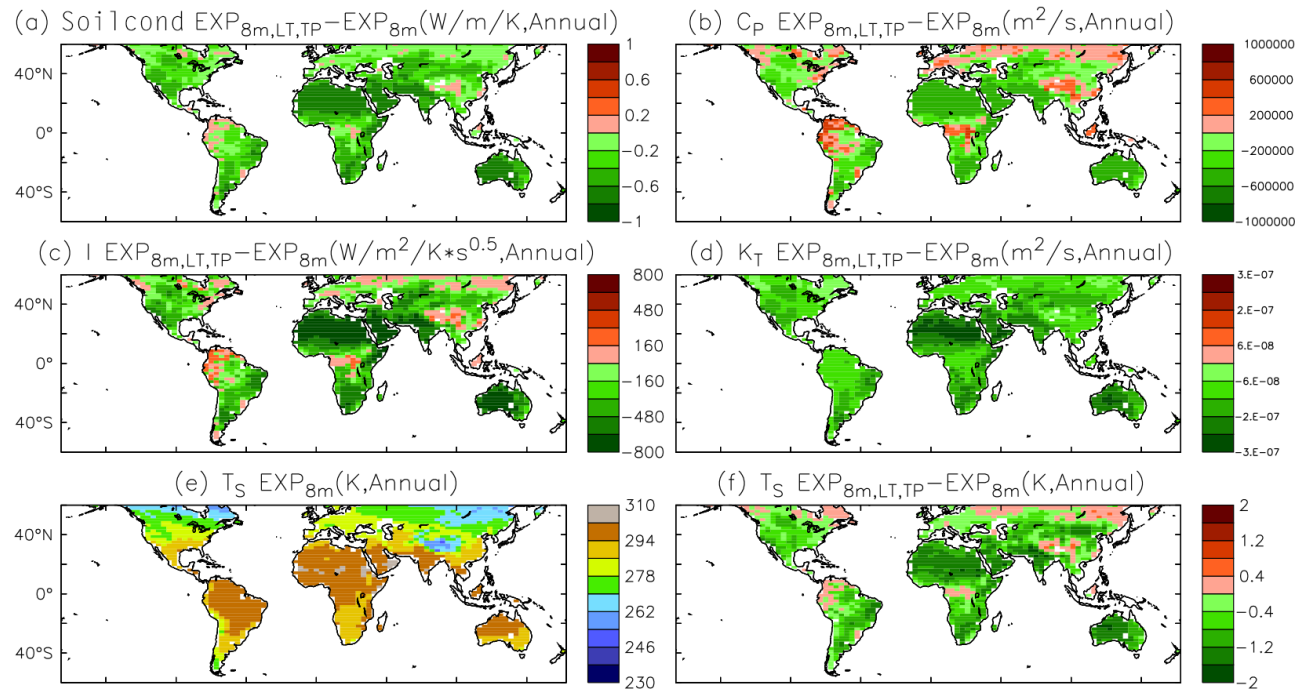

(f) $T_{S} \operatorname{EXP}_{8 m, L T, T P}-\operatorname{EXP}_{8 m}(K$, Annual $)$
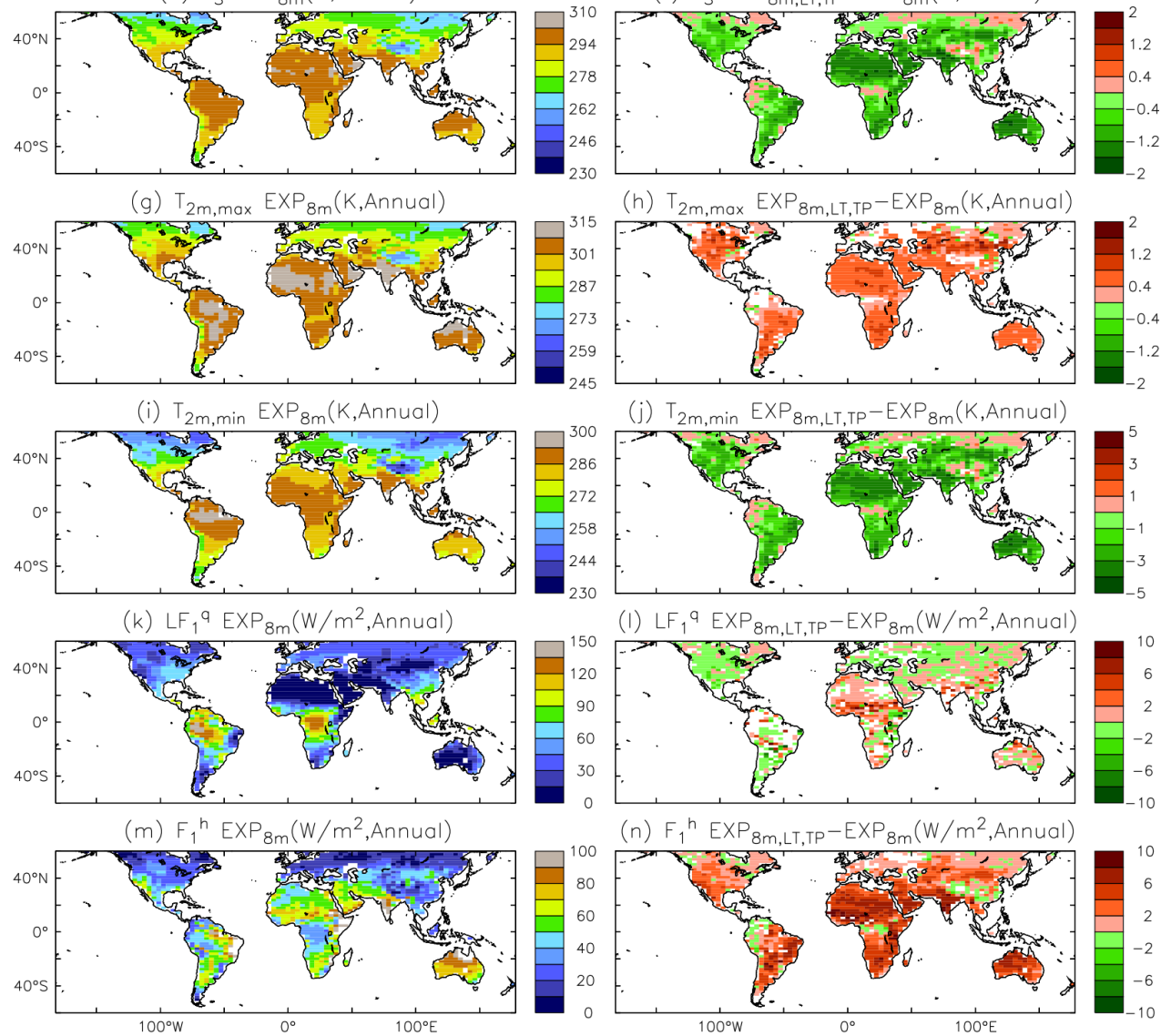

Figure 8. The LMDZOR simulations (annual mean) for $\operatorname{EXP}_{8 \mathrm{~m}}$ (left) and the differences between $\mathrm{EXP}_{8 \mathrm{~m}, \mathrm{LT}, \mathrm{TP}}(\mathrm{Table} 4)$ and EXP $8 \mathrm{~m}$ (right) for (a) soil thermal conductivity, (b) soil heat capacity, (c) soil thermal inertia, (d) soil heat diffusivity, (e, f) surface temperature, (g, h) daily maximum temperature, $(\mathbf{i}, \mathbf{j})$ daily minimum temperature, $(\mathbf{k}, \mathbf{l})$ latent heat flux, and $(\mathbf{m}, \mathbf{n})$ sensible heat flux. The white regions indicate that the new parameterizations are not significant.

thermal properties can be a source of bias and dispersion for the mean temperature as well as for its short-term variability in climate simulations.

Beyond the mean climate, the inter-diurnal distribution of the temperature is another important feature of the climate. In order to understand if and how it varies with the soil thermodynamics, the inter-diurnal temperature variability (Kim et al., 2013) of the daily mean (ITV) and of the minimum temperature $\left(\mathrm{IT}_{\mathrm{N}} \mathrm{V}\right)$ are evaluated for the control experiment and for the experiment with the full soil scheme. The ITV is calculated by averaging absolute inter-diurnal daily mean temperature $T_{2 \mathrm{~m}}$ differences over $n_{\mathrm{d}}$ days ( $n_{\mathrm{d}}$ is the number of days over 20 years), and $\mathrm{IT}_{\mathrm{N}} \mathrm{V}$ is calculated by averaging daily minimum temperature $T_{2 \mathrm{~m} \text {, min }}$ in the same way.

$\mathrm{ITV}=\frac{1}{n_{\mathrm{d}}-1} \sum_{i=1}^{n_{\mathrm{d}}-1}\left|T_{2 \mathrm{~m}, i+1}-T_{2 \mathrm{~m}, i}\right|$ 

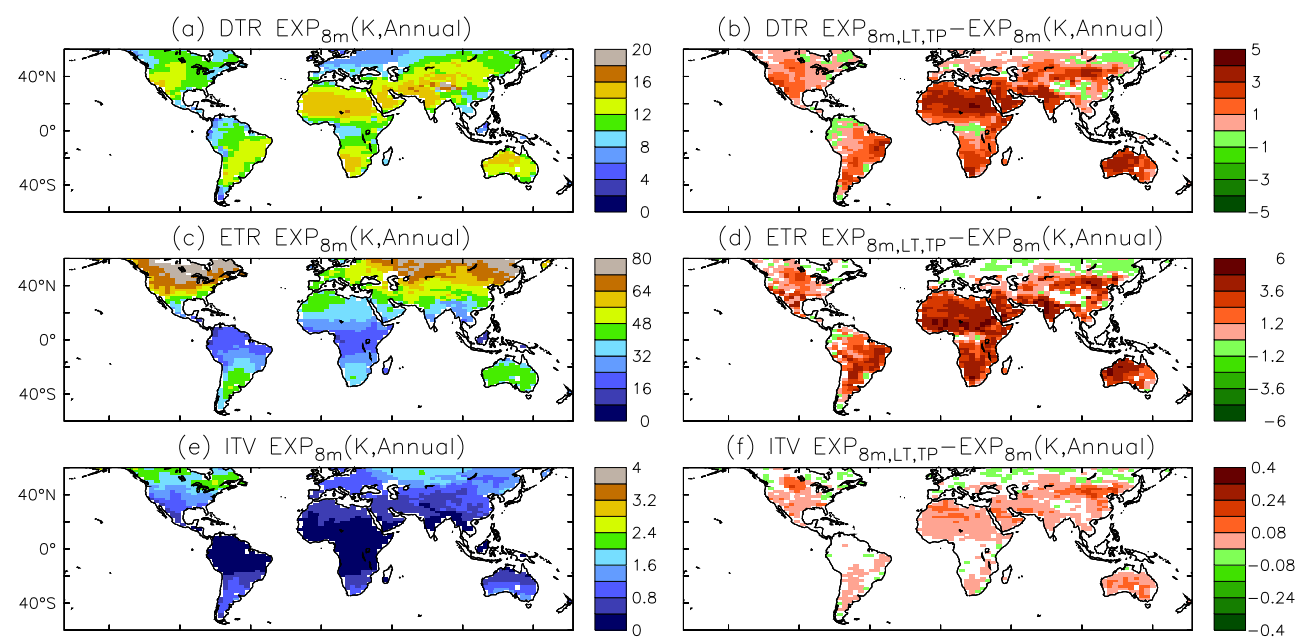

(g) $T_{N} \vee \operatorname{EXP}_{8 m}(K$, Annual)
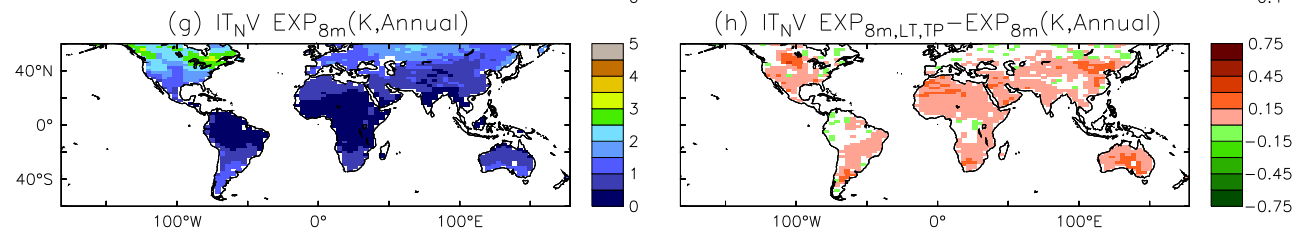

Figure 9. The extreme climate variables for $\operatorname{EXP}_{8 \mathrm{~m}}$ (left) and its difference with EXP $8 \mathrm{~m}, \mathrm{LT}, \mathrm{TP}$ (Table 4, right): (a, b) DTR; (c, d) ETR; (e, f) ITV; and $(\mathbf{g}, \mathbf{h}) \mathrm{IT}_{\mathrm{N}} \mathrm{V}$.

$\mathrm{IT}_{\mathrm{N}} \mathrm{V}=\frac{1}{n_{\mathrm{d}}-1} \sum_{i=1}^{n_{\mathrm{d}}-1}\left|T_{2 \mathrm{~m}, \min , i+1}-T_{2 \mathrm{~m}, \min , i}\right|$

Unlike the measures of mean climate variability, these variables capture the chronological sequence of the variable change throughout the whole period (Kim et al., 2013). The larger the ITV $\left(\mathrm{IT}_{\mathrm{N}} \mathrm{V}\right)$ is, the larger the difference of daily variable between two consecutive days. ITV increases by $0.1 \mathrm{~K}(10 \%$ of the average value) over $30 \%$ of the regions and by $0.2 \mathrm{~K}$ ( $5 \%$ of the average value) over $5 \%$ of the regions (e.g. China and the central US, Fig. $9 \mathrm{e}$ and f). $\mathrm{IT}_{\mathrm{N}} \mathrm{V}$ increases by $0.1-0.2 \mathrm{~K}(10-20 \%$ of the average value) over $50 \%$ of the regions and $0.3-0.4 \mathrm{~K}(30-40 \%)$ over $15 \%$ of the regions (e.g. the Sahara and western Australia, Fig. 9g and $\mathrm{h}$ ). These results are statistically significant at the $5 \%$ level ( $t$ test). To further analyze the results, the regional probability density function (PDF) of DTR and $\mathrm{IT}_{\mathrm{N}} \mathrm{V}$ are computed. Four regions are identified where DTR and $\mathrm{IT}_{\mathrm{N}} \mathrm{V}$ are largely affected by the modification of the soil thermal properties: the Sahara, the Sahel, central United States and North China (Fig. 10a and b, e and f, i and j, and $\mathrm{m}$ and $\mathrm{n}$, respectively). The PDF is asymmetrical with a heavier tail towards low values for DTR and towards high values for $\mathrm{IT}_{\mathrm{N}} \mathrm{V}$. However, the overall increase of the mean values for both DTR and $\mathrm{IT}_{\mathrm{N}} \mathrm{V}$ is mostly due to a widening of the distribution towards high values as depicted by the higher values of the 75 and 99 percentile (Fig. 10c and d, g and h, k and 1, and o and $\mathrm{p}$ ) and the increased standard deviation and skewness.
The general increase of $\mathrm{IT}_{\mathrm{N}} \mathrm{V}$ is associated with an increased frequency of extreme values over the Sahara, the Sahel, and North China, in which the $\mathrm{IT}_{\mathrm{N}} \mathrm{V}$ at 99 percentile increases by $18.78,18.96$, and $9.59 \%$, respectively. The variation of ITV is smaller than $\mathrm{IT}_{\mathrm{N}} \mathrm{V}$ (not shown).

Cattiaux et al. (2015) mentioned that extreme ITV and DTR values over Europe will tend to happen more frequently by the end of 21 century. They attributed these variations to dryer summers, reduced cloud cover and changes in largescale dynamics. In the present climate, DTR over Europe is weakly sensitive to soil thermodynamics. However, since the soil is projected to dry over part of Europe, the soil thermal properties are a potential source of dispersion for the climate projection over Europe, as it is already the case for arid and semi-arid areas. Because of this, the soil thermal properties can contribute to the uncertainties in simulations of extreme events such as heat waves for the present (e.g. Schär et al., 2004) as well as for the future (e.g. Cattiaux et al., 2015).

\section{Discussion}

In the new vertical discretization, the location of the bottom boundary has been shifted from $5 \mathrm{~m}$ (standard ORCHIDEE) to $8 \mathrm{~m}$ to insure the zero flux condition to be satisfied even for very moist soils with the coarser texture (among three classes) and over a seasonal cycle. It is planned to use the more detailed USDA texture description relying on 12 classes (Reynolds et al., 2000). For the coarser classes, preliminary tests indicate that the bottom layer might have to 

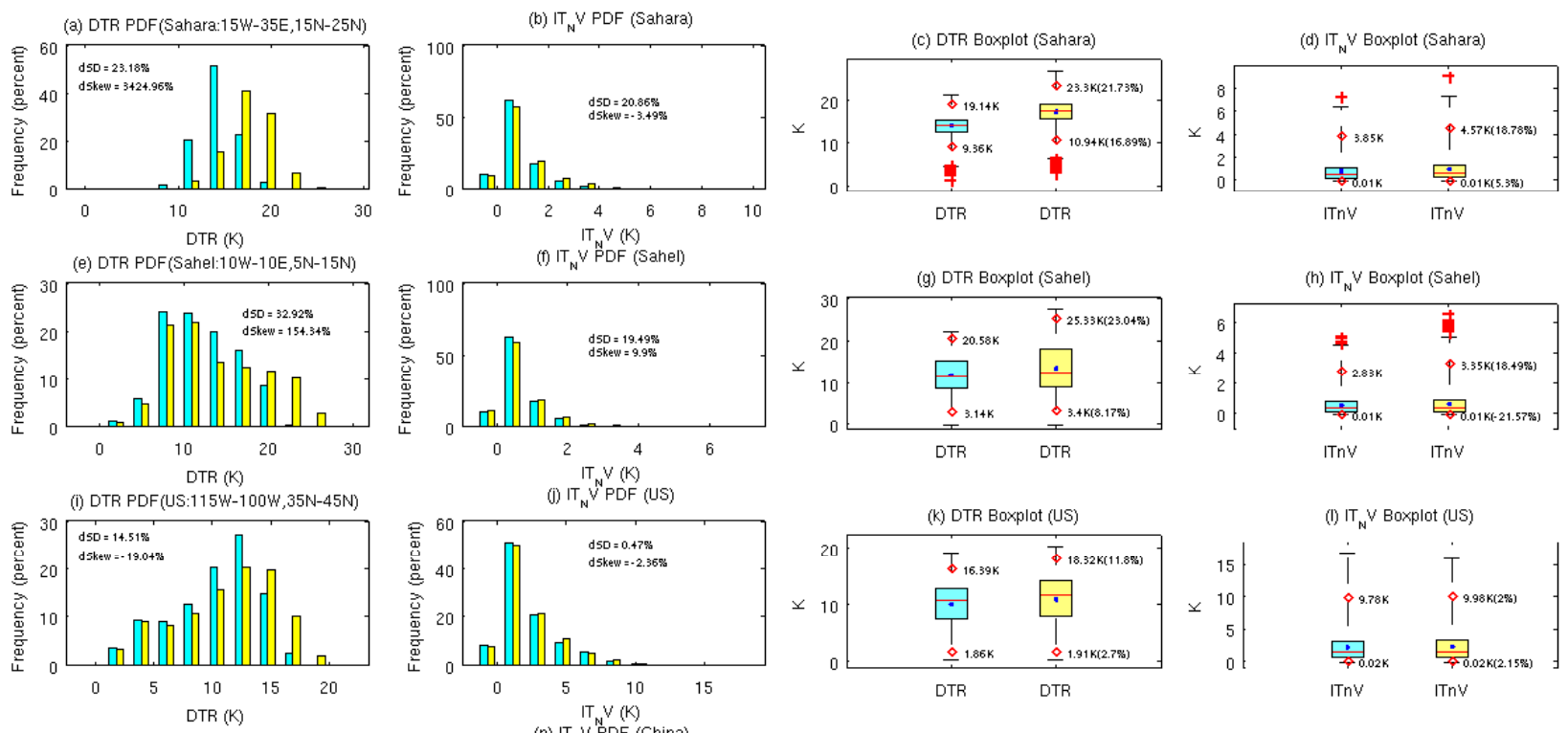

(m) DTR PDF(China $100 \mathrm{E}-120 \mathrm{E}, 40 \mathrm{~N}-50 \mathrm{~N})$
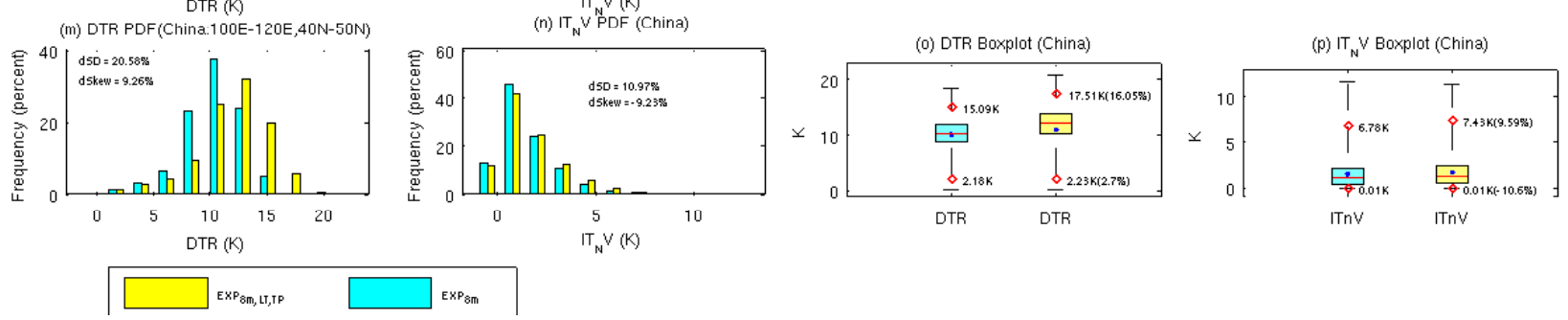

Figure 10. The probability density function (PDF) for DTR (1 column) and $\mathrm{IT}_{\mathrm{N}} \mathrm{V}$ ( 2 column), and the box plot of DTR (3 column) and $\mathrm{IT}_{\mathrm{N}} \mathrm{V}(4$ column) over the Sahara (1 line), the Sahel (2 line), the central US (3 line), and North China (4 line) between EXP $8 \mathrm{~m}, \mathrm{LT}, \mathrm{TP}$ (in yellow) and $\mathrm{EXP}_{8 \mathrm{~m}}$ (in blue) with daily values. The grid point value is weighted by its areas. In the box plot, the red central mark and the blue dot are the median and mean, and the edges of the box and the 25 and 75 percentiles. The whiskers extend to the most extreme data points not considered outliers. Points are drawn as outliers if they are larger than $X_{25 \text { th }}+3 \cdot\left(X_{75}\right.$ th $\left.-X_{25 \text { th }}\right)$ or smaller than $X_{25 \text { th }}-3 \cdot\left(X_{75 \text { th }}-X_{25 \text { th }}\right)$, where $X_{25 \text { th }}$ and $X_{75 \text { th }}$ are the 25 and 75 percentiles, respectively. The red diamond and the values are the 99 and 1 percentiles. The percentage $(\%, \mathrm{dSD}, \mathrm{dSk}$ ewness in PDF; values in brackets in box plot) measures the difference between the two simulations: $\left(\mathrm{EXP}_{8 \mathrm{~m}, \mathrm{LT}, \mathrm{TP}}-\mathrm{EXP}_{8 \mathrm{~m}}\right) / \mathrm{EXP}_{8 \mathrm{~m}} \cdot 100 \%$.

be shifted to $10 \mathrm{~m}$ (instead of $8 \mathrm{~m}$ ) to satisfy the zero flux condition. This paper focused on the improvement of the soil thermodynamics in LSM. However the choice of a $10 \mathrm{~m}$ deep soil can have important consequences on the modeling of the hydrological processes. On the one hand, Decharme et al. (2013) pointed out that to properly simulate the water budget and the river discharge over France, the soil depth for the hydrology should not exceed $1-3 \mathrm{~m}$. On the other hand, Hagemann and Stacke (2014) implemented a 5-layer soil depth $(\sim 10 \mathrm{~m})$ scheme in JSBACH model, and the hydrological cycles were well simulated over major river basins around the world. In addition, with a deeper soil the duration of the spin-up required to reach equilibrium conditions for the soil moisture is increased, which might be an issue for computing resources. However, if different depths are chosen for the moisture and for the temperature, caution is required when computing the moisture-dependent thermal properties beyond the boundary of the hydrological model.
The parameterization of the soil thermal properties can be responsible for temperature bias over dry areas in state-ofthe-art climate models simulations and potentially affect the representation of extreme by increasing the frequency of occurrence of the warmest temperature. These extreme values are probably underestimated in the current study because the nudging approach does not account for the coupling with atmospheric circulation and the related amplification effects. Because the soil thermal properties control the amplitude of the nocturnal cooling, it can modulate the results of impact studies related to the societal and eco-system impacts of the heat waves, which are due both to the maximum temperature and the amplitude of the nocturnal cooling (e.g., crop and pest development prediction, photosynthetic rates) (Lobell and Field, 2007). Diagnostics relying on this parameterization should thus be useful when defining multi-model climate experiments.

This paper deals with the physical parameterization of the soil thermodynamics. When focusing on an individual pro- 
cess and because of error compensation, the comparison with observations can be misleading for the evaluation of the improvements. For this reason, we choose to present the results as a sensitivity study. The improvements are reflected by increasing the realism of models in the aspects of the soil thermal properties (taking into account soil texture effects), soil vertical layers (consistent between water and temperature), and soil heat transfer process (coupled heat conduction and convection). The new developments together with the sensitivity experiments improve the understanding of the role of these factors in climate modeling.

\section{Summary}

In this paper an improved scheme for the soil thermodynamics has been described and implemented in the ORCHIDEE LSM. The new scheme uses a common discretization when solving the heat and moisture transfer into the soil. In the upper $2 \mathrm{~m}$, the discretization in the standard ORCHIDEE version is optimized for the moisture transfer and for the most nonlinear process, in the standard ORCHIDEE version (de Rosnay et al., 2000). The node distance of each layer below $2 \mathrm{~m}$ is set to $1 \mathrm{~m}$, which is the largest node distance for the standard ORCHIDEE version. In addition to the heat conduction, a parameterization of the heat transport by liquid water in the soil has been introduced. The soil thermal properties are parameterized as a function of the soil moisture and the soil texture. The new scheme has been first evaluated in a 1-D framework. The results of the implemented new scheme have been compared to the analytical solution corresponding to an imposed forcing representing an idealized diurnal or annual cycle of incoming radiative energy.
The impact of the soil thermodynamics on the energy surface budget and near-surface variables has been evaluated in a full 3-D framework where ORCHIDEE is coupled to the LMDZ atmospheric model. A nudging approach has been used. It prevents the use of time-consuming long-term simulations required to account for the natural variability of the climate and enables the representation of the effects of the modified parameterizations. The impact of the energy transported by the liquid water on the soil thermodynamics and on the near-surface meteorology is rather weak. In contrast, the introduction of a moisture/texture dependence of the thermal properties has a noticeable effect on the near-surface meteorology. The response of the diurnal cycle of the energy budget at the surface to a modification of the soil thermal properties is strongly asymmetric and is most pronounced during the night. The revised soil thermal properties induce a mean cooling, a mean increase of the diurnal temperature range and a mean increase of the intra-annual extreme temperature range. The short-term variability depicted by the interdiurnal temperature variability of the daily mean (ITV) and of the minimum temperature $\left(\mathrm{IT}_{\mathrm{N}} \mathrm{V}\right)$ is also partially controlled by the soil thermal properties. The effects of soil thermal properties on ITV and $\mathrm{IT}_{\mathrm{N}} \mathrm{V}$ are most pronounced over arid and semi-arid areas, where the thermal inertia of the soil is the lowest. The overall increase of the mean values for both DTR and ITV is mostly due to a widening of the distribution towards high values (e.g., 75 and 99 percentile) and to the increased standard deviation, manifesting a more frequent occurrence of extreme values. 
Appendix A: The numerical scheme for solving the coupled conduction-convection model

The $T$ and $\theta$ are calculated at the node, whereas the $q_{\mathrm{L}}$ is calculated at the interface. The evolution of the temperature in the middle of the layer is given by ( $S=0$ in Eq. 1)

$$
\begin{aligned}
C_{\mathrm{P}}^{t}(\theta, \mathrm{st})_{k+1 / 2} \frac{T_{k+1 / 2}^{t+\delta t}-T_{k+1 / 2}^{t}}{\delta t} & \\
= & \frac{1}{z_{k+1}-z_{k}}\left[\lambda(\theta, \mathrm{st})_{k+1} \frac{T_{k+3 / 2}^{t+\delta t}-T_{k+1 / 2}^{t+\delta t}}{z_{k+3 / 2}-z_{k+1 / 2}}\right. \\
& \left.-\lambda(\theta, \mathrm{st})_{k} \frac{T_{k+1 / 2}^{t+\delta t}-T_{k-1 / 2}^{t+\delta t}}{z_{k+1 / 2}-z_{k-1 / 2}}\right] \\
& +\frac{1}{z_{k+1}-z_{k}}\left[C _ { \mathrm { W } } q _ { \mathrm { L } , k } \left(w T_{k}^{t+\delta t}+(1\right.\right. \\
& \left.-w) T_{k}^{t}-T_{k+1 / 2}^{t+\delta t}\right)-C_{\mathrm{W}} q_{\mathrm{L}, k+1}\left(w T_{k+1}^{t+\delta t}\right. \\
& \left.\left.+(1-w) T_{k+1}^{t}-T_{k+1 / 2}^{t+\delta t}\right)\right]
\end{aligned}
$$

where $w$ is the weighting factor for implicit $(w=1)$ or semiimplicit $(w=0.5)$ solution. The soil temperature at the interface of soil layer ( $T_{k}$ for example) is calculated by a linear interpolation method according to the distance to the two nearest nodes:

$T_{k}^{t+\delta t}=g_{k} T_{k+1 / 2}^{t+\delta t}+h_{k} T_{k-1 / 2}^{t+\delta t}$,

$g_{k}=\frac{z_{k}-z_{k-1 / 2}}{z_{k+1 / 2}-z_{k-1 / 2}}$,

$h_{k}=\frac{z_{k+1 / 2}-z_{k}}{z_{k+1 / 2}-z_{k-1 / 2}}$,

At the surface, the boundary conditions are written as

$$
\begin{aligned}
& C_{\mathrm{P}}^{t}(\theta, \mathrm{st})_{1 / 2} \frac{T_{1 / 2}^{t+\delta t}-T_{1 / 2}^{t}}{\delta t} \\
& =\frac{1}{z_{1}-z_{0}}\left[\lambda(\theta, \mathrm{st})_{1} \frac{T_{3 / 2}^{t+\delta t}-T_{1 / 2}^{t}}{z_{3 / 2}-z_{1 / 2}}\right]+\sum F^{\downarrow}\left(T_{\mathrm{S}}^{t}\right) \\
& -\varepsilon \sigma T_{\mathrm{S}}^{4}+\frac{1}{z_{1}-z_{0}}\left\{C _ { \mathrm { W } } q _ { \mathrm { L } , 0 } \left[w\left(g_{0} T_{1 / 2}^{t+\delta t}+h_{0} T_{-1 / 2}^{t+\delta}\right)\right.\right. \\
& \left.+(1-w)\left(g_{0} T_{1 / 2}^{t}+h_{0} T_{-1 / 2}^{t}\right)-T_{1 / 2}^{t+\delta t}\right] \\
& -C_{\mathrm{W}} q_{\mathrm{L}, 1}\left[w\left(h_{1} T_{1 / 2}^{t+\delta t}+g_{1} T_{3 / 2}^{t+\delta t}\right)\right. \\
& \left.\left.+(1-w)\left(h_{1} T_{1 / 2}^{t}+g_{1} T_{3 / 2}^{t}\right)-T_{1 / 2}^{t+\delta t}\right]\right\}
\end{aligned}
$$

and at the bottom with zero flux boundary condition:

$$
\begin{aligned}
& C_{\mathrm{P}}^{t}(\theta, \mathrm{st})_{N-1 / 2} \frac{T_{N-1 / 2}^{t+\delta t}-T_{N-1 / 2}^{t}}{\delta t} \approx \frac{1}{z_{N}-z_{N-1}} \\
& {\left[-\lambda(\theta, \mathrm{st})_{N-1} \frac{T_{N-1 / 2}^{t+\delta t}-T_{N-3 / 2}^{t+\delta t}}{z_{N-1 / 2}-z_{N-3 / 2}}\right]+\frac{1}{z_{N}-z_{N-1}}} \\
& \left\{C _ { \mathrm { W } } q _ { \mathrm { L } , N - 1 } \left[w\left(g_{N-1} T_{N-1 / 2}^{t+\delta t}+h_{N-1} T_{N-3 / 2}^{t+\delta t}\right)\right.\right. \\
& +(1-w)\left(g_{N-1} T_{N-1 / 2}^{t}+h_{N-1} T_{N-3 / 2}^{t}\right) \\
& \left.-T_{N-1 / 2}^{t+\delta t}\right]-C_{\mathrm{W}} q_{\mathrm{L}, N}\left[w T_{N-1 / 2}^{t+\delta t}\right. \\
& \left.\left.+(1-w) T_{N-1 / 2}^{t}-T_{N-1 / 2}^{t+\delta t}\right]\right\} \text {. }
\end{aligned}
$$

\section{Appendix B: The soil vertical discretization}

\section{B1 The 5M7L method}

In the 5M7L method, the thickness of each layer is geometrically distributed with soil depth (Fig. 2a). The depth at the node $z z_{i}(\mathrm{~m})$, the depth at the layer interface $\left(z l_{i}, \mathrm{~m}\right)$, and the thickness of each layer $\left(\Delta z_{i}, \mathrm{~m}\right)$ are computed as follows:

$$
\begin{aligned}
& z z_{i}=0.3 \times \sqrt{\frac{\tau}{\pi} \times \frac{\lambda}{C_{\mathrm{P}}}} \times\left(2^{i-1 / 2}-1\right), 1 \leq i \leq N_{7 L}, \\
& z l_{i}=0.3 \times \sqrt{\frac{\tau}{\pi} \times \frac{\lambda}{C_{\mathrm{P}}}} \times\left(2^{i}-1\right), \quad 1 \leq i \leq N_{7 L}, \\
& \Delta z_{i}=0.3 \times \sqrt{\frac{\tau}{\pi} \times \frac{\lambda}{C_{\mathrm{P}}}} \times\left(2^{i}-2^{i-1}\right), 1 \leq i \leq N_{7 L},
\end{aligned}
$$

\section{B2 The 2M11L method}

In the $2 \mathrm{M} 11 \mathrm{~L}$ method (Fig. $2 \mathrm{~b}$ ), the $z z_{i}, \Delta z_{i}$, and $z l_{i}$ are computed as follows:

$$
\begin{aligned}
& z z_{i}=2 \times \frac{2^{i-1}-1}{2^{N_{11 L}-1}-1}, 1 \leq i \leq N_{11 L}, \\
& \Delta z_{i}=\left\{\begin{array}{c}
0.5 \times\left(z z_{2}-z z_{1}\right), \quad i=1 \\
0.5 \times\left[\left(z z_{i}-z z_{i-1}\right)+\left(z z_{i+1}-z z_{i}\right)\right] \\
2 \leq i \leq N_{11 L}-1 \\
0.5 \times\left(z z_{N}-z z_{N-1}\right), \quad i=N_{11 L},
\end{array}\right. \\
& z l_{i}=\left\{\begin{array}{c}
\Delta z_{1}, \quad i=1 \\
z l_{i-1}+\Delta z_{i}, \quad 2 \leq i \leq N_{11 L},
\end{array}\right.
\end{aligned}
$$

\section{B3 The 8M17L method}

In the $8 \mathrm{M} 17 \mathrm{~L}$ discretization (Fig. 2c), the $z z_{i}, \Delta z_{i}$, and $z l_{i}$ are computed as follows (the $z z_{17}$ of temperature is in the 
middle of the last layer; Table 3):

$$
z z_{i}=\left\{\begin{array}{c}
0.5 \times \frac{2^{2-1}-1}{2^{N_{11 L}-1}-1} \quad \text { for temperature; } \\
0 \text { for moisture; } \quad i=1 \\
2.0 \times \frac{2^{i-1}-1}{2^{N_{11 L}-1}-1}, \quad 2 \leq i \leq N_{11 L} \\
2+(i-11) \times\left(2 \times \frac{2^{N_{11 L}-1}-1}{2^{N_{11 L}-1}-1}\right. \\
\left.-2 \times \frac{2^{N_{10 L}-1}-1}{2^{N_{11 L}-1}-1}\right), N_{11 L}<i \leq N_{17 L}
\end{array}\right.
$$

$$
\begin{gathered}
\Delta z_{i}=\left\{\begin{array}{c}
0.5 \times\left(z z_{2}-0\right), \quad i=1 \\
0.5 \times\left[\left(z z_{i}-z z_{i-1}\right)+\left(z z_{i+1}-z z_{i}\right)\right] \\
2 \leq i \leq N_{17 L}-1, \text { with } z z_{1}=0 \\
0.5 \times\left(z z_{N}-z z_{N-1}\right), \quad i=N_{17 L},
\end{array}\right. \\
z l_{i}=\left\{\begin{array}{l}
\Delta z_{1}, \quad i=1 \\
z l_{i-1}+\Delta z_{i}, \quad 2 \leq i \leq N_{17 L} .
\end{array}\right.
\end{gathered}
$$




\section{Code availability}

The ORCHIDEE and LMDZ model source code can be obtained from http://forge.ipsl.jussieu.fr/orchidee and http:// web.lmd.jussieu.fr/trac/browser. Additional information and the LMDZOR code with new thermodynamics implemented can be obtained on request. All the code can only be used for non-commercial academic research purpose.

Acknowledgement. The authors gratefully acknowledge financial support provided by the EMBRACE project (grant no. 282672) within the Framework Program 7 (FP7) of the European Union. We also express our thanks to Agnès Ducharne and Frédéric Hourdin for the valuable discussions. We thank the two anonymous reviewers, whose comments helped improve this manuscript.

Edited by: D. Lawrence

\section{References}

Ait-Mesbah, S., Dufresne, J.-L., Cheruy, F., and Hourdin, F.: Mean and diurnal range of surface temperature over semi-arid and arid regions depend strongly on soil thermal inertia, Geophys. Res. Lett., 42, 7572-7580, doi:10.1002/2015GL065553, 2015.

Anderson, J. L., Balaji, V., Broccoli, A. J., Cooke, W. F., Delworth, T. L., Dixon, K. W., Donner, L. J., Dunne, K. A., Freidenreich, S. M., Garner, S. T., Gudgel, R. G., Gordon, C. T., Held, I. M., Hemler, R. S., Horowitz, L. W., Klein, S.A., Knutson, T. R., Kushner, P. J., Langenhorst, A. R., Lau, N.-C., Liang, Z., Malyshev, S. L., Milly, P. C. D., Nath, M. J., Ploshay, J. J., Ramaswamy, V., Schwarzkopf, M. D., Shevliakova, E., Sirutis, J. J., Soden, B. J., Stern, W. F., Thompson, L. A., John Wilson, R., Wittenberg, A. T., and Wyman, B. L.: The new GFDL global atmosphere and land model AM2-LM2: Evaluation with prescribed SST simulations, J. Climate, 17, 4641-4673, doi:10.1175/JCLI-3223.1, 2004.

Abu-Hamdeh, N. H.: Thermal properties of soils as affected by density and water content, Biosyst. Eng., 86, 97-102, doi:10.1016/S1537-5110(03)00112-0, 2003.

Balsamo, G., Beljaars, A., Scipal, K., Viterbo, P., van den Hurk, B., Hirschi, M., and Betts, A. K.: A revised hydrology for the ECMWF Model: verification from field site to terrestrial water storage and impact in the integrated forecast system, J. Hydrometeorol., 10, 623-643, doi:10.1175/2008JHM1068.1, 2009.

Best, M. J., Pryor, M., Clark, D. B., Rooney, G. G., Essery, R .L. H., Ménard, C. B., Edwards, J. M., Hendry, M. A., Porson, A., Gedney, N., Mercado, L. M., Sitch, S., Blyth, E., Boucher, O., Cox, P. M., Grimmond, C. S. B., and Harding, R. J.: The Joint UK Land Environment Simulator (JULES), model description - Part 1: Energy and water fluxes, Geosci. Model Dev., 4, 677==699, doi:10.5194/gmd-4-677-2011, 2011.

Cattiaux, J., Douville, H., Schoetter, R., Parey, S., and Yiou, P.: Projected increase in diurnal and inter diurnal variations of European summer temperatures, Geophys. Res. Lett., 42, 899-907, doi:10.1002/2014GL062531, 2015.

Cheruy, F., Campoy, A., Dupont, J. C., Ducharne, A., Hourdin, F., Haeffelin, M., Chiriaco, M., and Idelkadi, A.: Combined influ- ence of atmospheric physics and soil hydrology on the simulated meteorology at the SIRTA atmospheric observatory, Clim. Dynam., 40, 2251-2269, doi:10.1007/s00382-012-1469-y, 2013.

Cheruy, F., Dufresne, J. L., Hourdin, F., and Ducharne, A.: Role of clouds and land-atmosphere coupling in midlatitude continental summer warm biases and climate change amplification in CMIP5 simulations, Geophys. Res. Lett., 41, 6493-6500, doi:10.1002/2014GL061145, 2014.

Coindreau, O., Hourdin, F., Haeffelin, M., Mathieu, A., and Rio, C.: Assessment of physical parameterizations using a global climate model with stretchable grid and Nudging, Mon. Weather Rev., 135, 1474-1489, doi:10.1175/MWR3338.1, 2007.

Cox, P. M., Betts, R. A., Bunton, C. B., Essery, R. L. H., Rowntree, P. R., and Smith, J.: The impact of new land surface physics on the GCM simulation of climate and climate sensitivity, Clim. Dynam., 15, 183-203, 1999.

Decharme, B., Martin, E., and Faroux, S.: Reconciling soil thermal and hydrological lower boundary conditions in land surface models, J. Geophys. Res.-Atmos., 118, 7819-7834, doi:10.1002/jgrd.50631, 2013.

De Rosnay, P., Bruen, M., and Polcher, J.: Sensitivity of the surface fluxes tothe number of layers in the soil model used for GCMs, Geophys. Res. Lett., 27, 3329-3332, 2000.

De Vries, D. A.: Thermal properties of soils, in: Physics of Plant Environment, edited by: Wijk, W. R. V., John Wiley and Sons, 210-235, 1963.

Dufresne, J. -L., Foujols, M, -A., Denvil, S., Caubel, A., Marti, O., Aumont, O., Balkanski, Y., Bekki, S., Bellenger, H., Benshila, R., Bony, S., Bopp, L., Braconnot, P., Brockmann, P., Cadule, P., Cheruy, F., Codron, F., Cozic, A, Cugnet, D., De Noblet, N., Duvel, J. -P., Ethe, C., Fairhead, L., Fichefet, T., Flavoni, S., Friedlingstein, P., Grandpeix, J. -Y., Guez, L., Guilyardi, E., Hauglustaine, D., Hourdin, F., Idelkadi, A., Ghattas, J., Joussaume, S., Kageyama, M., Krinner, G., Labetoulle, S., Lahellec, A., Lefebvre M.-P., Lefevre, F., Levy, C., Li, Z. X., Lloyd, J., Lott, F., Madec, G., Mancip, M., Marchand, M., Masson, S., Meurdesoif, Y., Mignot, J., Musat, I., Parouty, S., Polcher, J., Rio, C., Schulz, M., Swingedouw, D., Szopa, S., Talandier, C., Terray, P., Viovy, N., and Vuichard, N.: Climate change projections using the IPSLCM5 Earth System Model: from CMIP3 to CMIP5, Clim. Dynam., 40, 2123-2165, doi:10.1007/s00382-012-1636-1, 2013.

Ek, M. B., Mitchell, K. E., Lin, Y., Rogers, E., Grunmann, P., Koren, V., Gayno, G., and Tarpley, J. D.: Implementation of Noah land surface model advances in the National Centers for Environmental Prediction operational mesoscale Eta model, J. Geophys. Res., 108, 8851, doi:10.1029/2002JD003296, 2003.

Ekici, A., Beer, C., Hagemann, S., Boike, J., Langer, M., and Hauck, C.: Simulating high-latitude permafrost regions by the JSBACH terrestrial ecosystem model, Geosci. Model Dev., 7, 631-647, doi:10.5194/gmd-7-631-2014, 2014.

Forster, P. M. F. and Taylor, K. E.: Climate forcings and climate sensitivities diagnosed from Coupled Climate Model Integrations, J Climate, 19, 6181-6194, doi:10.1175/JCLI3974.1, 2006.

Gao, Z., Fan, X., and Bian, L.: An analytical solution to onedimensional thermal conduction-convection in soil, Soil Sci., 168, 99-107, 2003.

Gao, Z., Lenschow, D. H., Horton, R., Zhou, M., Wang, L., and Wen, J.: Comparison of two soil temperature algorithms for 
a bare ground site on the Loess Plateau in China, J. Geophys. Res.-Atmos., 113, D18105, doi:10.1029/2008JD010285, 2008.

Garcia Gonzalez, R., Verhoef, A., Luigi Vidale, P., and Braud, I.: Incorporation of water vapor transfer in the JULES land surface model: implications for key soil variables and land surface fluxes, Water Resour. Res., 48, W05538, doi:10.1029/2011WR011811, 2012.

Gosnell, R., Fairall, C. W., and Webster, P. J.: The sensible heat of rainfall in the tropical ocean, J. Geophys. Res., 100, 1843718442, doi:10.1029/95JC01833, 1995.

Gouttevin, I., Krinner, G., Ciais, P., Polcher, J., and Legout, C.: Multi-scale validation of a new soil freezing scheme for a landsurface model with physically-based hydrology, The Cryosphere, 6, 407-430, doi:10.5194/tc-6-407-2012, 2012.

Hagemann, S. and Stacke, T.: Impact of the soil hydrology scheme on simulated soil moisture memory, Clim. Dynam., 44, 17311750, doi:10.1007/s00382-014-2221-6, 2014.

Hazeleger, W., Wang, X., Severijns, C., Stefanescu, S., Bintanja, R., Sterl, A., Wyser, K., Semmler, T., Yang, S., van den Hurk, B., van Noije, T., van der Linden, E., and van der Wiel, K.: EC-earth V2.2: Description and validation of a new seamless Earth system prediction model, Clim. Dynam., 39, 2611-2629, doi:10.1007/s00382-011-1228-5, 2011.

Hourdin, F.: Etude et simulation numérique de la circulation générale des atmosphères planétaires, $\mathrm{PhD}$ Thesis, available at: www.lmd.jussieu.fr/ hourdin/these.pdf (last access: 24 January 2016), 1992.

Hourdin, F., Grandpeix, J.-Y., Rio, C., Bony, S., Jam, A., Cheruy, F., Rochetin, N., Fairhead, L., Idelkadi, A., Musat, I., Dufresne, J.L., Lefebvre, M.-P., Lahellec, A., and Roehrig, R.: LMDZ5B: the atmospheric component of the IPSL climate model with revisited parameterizations for clouds and convection, Clim. Dynam., 40, 2193-2222, doi:10.1007/s00382-012-1343-y, 2013.

Johansen, O.: Thermal conductivity of soils (in Norwegian), PhD Thesis, Univ. of Trondheim, Trondheim, Norway, 1975 (English Translation, No. 637, U.S. Army Cold Regions Research and Enginering Laboratory, Hanover, New Hampshire, July 1977).

Kim, O. Y., Wang, B., and Shin, S. H.: How do weather characteristics change in a warming climate?, Clim. Dynam., 41, 32613281, doi:10.1007/s00382-013-1795-8, 2013.

Kollet, S. J., Cvijanovic, I., Schüttemeyer, D., Maxwell, R. M., Moene, A. F., and Bayer, P.: The influence of rain sensible heat and subsurface energy transport on the energy balance at the land surface, Vadose Zone J., 8, 846-857, doi:10.2136/vzj2009.0005, 2009.

Kooperman, G. J., Pritchard, M. S., Ghan, S. J., Wang, M., Somerville, R. C. J., and Russell, L. M.: Constraining the influence of natural variability to improve estimates of global aerosol indirect effects in a nudged version of the Community Atmosphere Model 5, J. Geophys. Res., 117, D23204, doi:10.1029/2012JD018588, 2012.

Koster, R. D., Dirmeyer, P. A., Guo, Z. C., Bonan, G. B., Chan, E., Cox, P., Gordon, C. T., Kanae, S., Kowalczyk, E., Lawrence, D., Liu, P., Luo, C. H., Malyshev, S., McAvaney, B., Mitchell, K., Mocko, D., Oki, T., Oleson, K., Pitman, A., Sud, Y. C., Taylor, C. M., Verseghy, D., Vasic, R., Xue, Y. K., and Yamada, T.: Regions of strong coupling between soil moisture and precipitation, Science, 305, 1138-1140, doi:10.1126/science.1100217, 2004.
Krinner, G., Viovy, N., de Noblet-Ducoudré, N., Ogée, J., Polcher, J., Friedlingstein, P., Ciais, P., Sitch, S., and Prentice, I. C.: A dynamic global vegetation model for studies of the coupled atmosphere-biosphere system, Global Biogeochem. Cy., 19, GB1015, doi:10.1029/2003GB002199, 2005.

Lawrence, D. M. and Slater, A. G.: Incorporating organic soil into a global climate model, Clim. Dynam., 30, 145-160, doi:10.1007/s00382-007-0278-1, 2008.

Lawrence, D. M., Slater, A. G., Romanovsky, V. E., and Nicolsky, D. J.: Sensitivity of a model projection of near-surface permafrost degradation to soil column depth and representation of soil organic matter, J. Geophys. Res., 113, F02011, doi:10.1029/2007JF000883, 2008.

Lawrence, D. M., Oleson, K. W., Flanner, M. G., Thornton, P. E., Swenson, S. C., Lawrence, P. J., Zeng, Z., Yang, Z.-L., Levis, S., Sakaguchi, K., Bonan, G. B., and Slater, A. G.: Parameterization improvements and functional and structural advances in version 4 of the Community Land Model, J. Adv. Model. Earth Syst., 3, 1-27, doi:10.1029/2011MS000045, 2011.

Lindvall, J. and Svensson, G.: The diurnal temperature range in the CMIP5 models, Clim. Dynam., 44, 405-421, doi:10.1007/s00382-014-2144-2, 2014.

Lobell, D. and Field, C.: Global scale climate-crop yield relationships and the impacts of recent warming, Environ. Res. Lett., 2, 014002, doi:10.1088/1748-9326/2/1/014002, 2007.

Lynch-Stieglitz, M.: The development and validation of a simple snow model for the GISS GCM, J. Climate, 7, 1842-1855, doi:10.1175/1520-0442(1994)007<1842:TDAVOA>2.0.CO;2, 1994.

Pielke Roger, A. Sr.: Mesoscale Meteorological Modeling, P414, 2nd Edn., Academic Press, 2002.

Peters-Lidard, C. D., Blackburn, E., Liang, X., and Wood, E. F.: The effect of soil thermal conductivity parameterization on surface energy fluxes and temperatures, J. Atmos. Sci., 55, 1209-1224, 1998.

Reynolds, C. A., Jackson, T. J., and Rawls. W. J.: Estimating soil water-holding capacities by linking the FAO soil map of the world with global pedon databases and continuous pedo transfer functions, Water Resour. Res., 36, 3653-3662, doi:10.1029/2000WR900130, 2000.

Rio, C., Grandpeix, J.-Y., Hourdin, F., Guichard, F., Couvreus, F., Lafore, J.-P., Fridlind, A., Mrowiec, A., Roehrig, R., Rochetin, N., Lefebvre, M.-P., and Idelkadi, A.: Control of deep convection by sub-cloud lifting processes: the ALP closure in the LMDZ5B general circulation model, Clim. Dynam., 40, 22712292, doi:10.1007/s00382-012-1506-x, 2013.

Saito, H., Simunek, J., and Mohanty, B. P.: Numerical analysis of coupled water, vapor, and heat transport in the Vadose Zone, Vadose Zone J., 5, 784-800, doi:10.2136/vzj2006.0007, 2006.

Schär, C., Vidale, P. L., Lüthi, D., Frei, C., Häberli, C., Liniger, M., and Appenzeller, C.: The role of increasing temperature variability in European summer heat waves, Nature, 427, 332-336, 2004.

Stevens, M. B., Smerdon, J. E., Gonzalez-Rouco, J. F., Stieglitz, M., and Beltrami, H.: Effects of bottom boundary placement on subsurface heat storage: implications for climate model simulations, Geophys. Res. Lett., 34, L02702, doi:10.1029/2006GL028546, 2007. 
Sun, S. and Zhang, X.: Effect of the lower boundary position of the Fourier equation on the soil energy balance, Adv. Atmos. Sci., 14, 868-878, doi:10.1007/BF02915589, 2004.

van den Hurk, B. J. J. M., Viterbo, P., Beljaars, A. C. M., and Betts, A. K.: Offiine validation of the ERA40 surface scheme, ECMWF Tech Memo 295, ECMWF, Reading, 42 pp., 2000.

Wei, N., Dai, Y., Zhang, M., Zhou, L., Ji, D., Zhu, S., and Wang, L.: Impact of precipitation-induced sensible heat on the simulation of land-surface air temperature, J. Adv. Model. Earth Syst., 6, 1311-1320, doi:10.1002/2014MS000322, 2014.
Yang, K. and Koike, T.: Comments on "Estimating soil water contents from soil temperature measurements by using an adaptive kalman filter”, J. Appl. Meteorol., 44, 546-550, 2005. 